NASA-CR-191239

DEPARTMENT OF MECHANICAL ENGINEERING \& MECHANICS

COLLEGE OF ENGINEERING \& TECHNOLOGY

OLD DOMINION UNIVERSITY

NORFOLK, VIRGINIA 23529

INVESTIGATION OF HYPERSONIC SHOCK-INDUCED

COMBUSTION IN A HYDROGEN-AIR SYSTEM

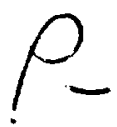

By

J.K. Ahuja, Graduate Research Assistant

S.N. Tiwari, Principal Investigator

and

D.J. Singh, Research Scientist

Progress Report

For the period ended June 30, 1992

Prepared for

National Aeronautics and Space Administration

Langley Research Center

Hampton, Virginia 23665

Under

Research Grant NAG-1-423

Drs. A. Kumar and J.P. Drummond, Technical Monitor FLDMD-Theoretical Flow Physics Branch

November 1992 
DEPARTMENT OF MECHANICAL ENGINEERING \& MECHANICS

COLLEGE OF ENGINEERING \& TECHNOLOGY

OLD DOMINION UNIVERSITY

NORFOLK, VIRGINIA 23529

INVESTIGATION OF HYPERSONIC SHOCK-INDUCED

COMBUSTION IN A HYDROGEN-AIR SYSTEM

By

J.K. Ahuja, Graduate Research Assistant

S.N. Tiwari, Principal Investigator

and

D.J. Singh, Research Scientist

Progress Report

For the period ended June 30, 1992

Prepared for

National Aeronautics and Space Administration

Langley Research Center

Hampton, Virginia 23665

Under

Research Grant NAG-1-423

Drs. A. Kumar and J.P. Drummond, Technical Monitor FLDMD-Theoretical Fiow Physics Branch

Submitted by the

old Dominion University Research Foundation

P.0. Box 6369

Norfolk, Virginia 23508-0369

November 1992 


\section{FOREWORD}

This is a progress report on the research project, "Analysis and Computation of Internal Flow Field in a Scramjet Engine," for the period ended June 30, 1992. Special attention during this period was directed to "Investigation of Hypersonic Shock-Induced Combustion in a Hydrogen-Air System." Important results of this study were presented at the AIAA 30th Aerospace Sciences Meeting, Reno, Nevada, January 6-9, 1992; AIAA paper no. 92-0339, January 1992. This paper is attached in this report as Appendix A.

This work was supported by the NASA Langley Research Center (Theoretical Flow Physics Branch of the Fluid Mechanics Division) through the grant NAG-1-423. The grant was monitored by Drs. A. Kumar and J. P. Drummond-Theoretical Flow Physics Branch. The work, in part, was also supported by the Old Dominion University's ICAM Program through NASA grant NAG-1-363; this grant was monitored by Mr. Robert L. Yang, Assistant University Affairs Officer, NASA Langley Research Center, Hampton, Virginia 23665-5225. 


\title{
INVESTIGATION OF HYPERSONIC SHOCK-INDUCED \\ COMBUSTION IN A HYDROGEN-AIR SYSTEM
}

\author{
J. K. Ahuja* and S. N. Tiwari ${ }^{\dagger}$ \\ Old Dominion University, Norfolk, VA 23508 \\ D. J. Singh $\ddagger$ \\ Analytical Services and Materials Inc., Hampton, VA 23666
}

\begin{abstract}
A numerical study is conducted to simulate the ballistic range experiments at Mach 5.11 and 6.46. The flow field is found to be unsteady with periodic instabilities originating in the stagnation zone. The unsteadiness of the flow field decreased with increase in the Mach number, thus indicating that it is possible to stabilize such flow fields with a high degree of overdrive. The frequency of periodic instability is determined using Fourier power spectrum and is found to be in good agreement with the experimental data. The physics of the instability is explained by the wave interaction models available in the literature.
\end{abstract}

\footnotetext{
* Graduate Research Assistant, Department of Mechanical Engineering and Mechanics

$\dagger$ Eminent Professor, Department of Mechanical Engineering and Mechanics

‡ Research Scientist, Analytical Services and Materials, Inc.
} 


\section{TABLE OF CONTENTS}

FOREWORD $\ldots \ldots \ldots \ldots \ldots \ldots \ldots \ldots \ldots \ldots \ldots \ldots \ldots \ldots \ldots \ldots \ldots \ldots \ldots$ iii

$-$

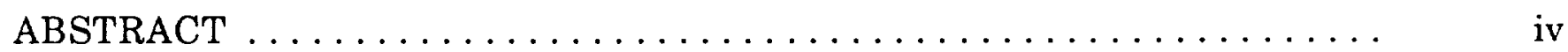

$-\quad$ LIST OF FIGURES $\ldots \ldots \ldots \ldots \ldots \ldots \ldots \ldots \ldots \ldots \ldots \ldots \ldots \ldots \ldots \ldots$

LIST OF SYMBOLS $\ldots \ldots \ldots \ldots \ldots \ldots \ldots \ldots \ldots \ldots \ldots \ldots \ldots \ldots \ldots \ldots \ldots$ vii

INTRODUCTION $\ldots \ldots \ldots \ldots \ldots \ldots \ldots \ldots \ldots \ldots \ldots \ldots \ldots \ldots \ldots \ldots \ldots$

BASIC GOVERNING EQUATIONS $\ldots \ldots \ldots \ldots \ldots \ldots \ldots \ldots \ldots \ldots$

CHEMISTRY AND THERMODYNAMIC MODELS $\ldots \ldots \ldots \ldots \ldots \ldots \ldots$

- METHOD OF SOLUTIONS ............................ 11

RESULTS AND DISCUSSIONS $\ldots \ldots \ldots \ldots \ldots \ldots \ldots \ldots \ldots \ldots \ldots \ldots \ldots \ldots$

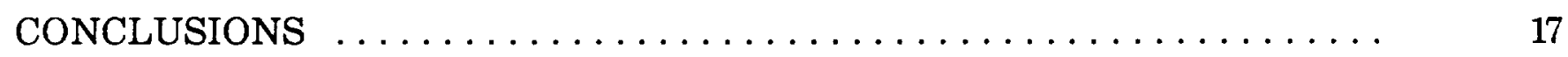

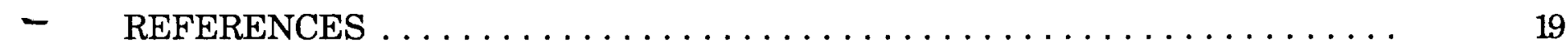

APPENDIX A: AIAA PAPER NO. 92-0339 


\section{LIST OF FIGURES}

Figure $\quad$ Page

1. Shadowgraph of a spherical nose projectile moving at Mach 5.11 into a 21 premixed stoichiometric hydrogen-air mixture

2. Shadowgraph of a spherical nose projectile moving at Mach 6.46 into a 22 premixed stoichiometric hydrogen-air mixture

3. Typical grid for the calculation 23

4. Density contours for the Mach 5.11

5. Enlarged view of density contours for Mach 5.11

6. Temperature contours for Mach $5.11 \quad 26$

7. Enlarged view of temperature contours for Mach $5.11 \quad 27$

8. Temperature vs radius along various $j=$ constant grid lines 28

9. Water mass fraction contours for Mach 5.11

10. Enlarged view of $\mathrm{H}_{2} \mathrm{O}$ mass fraction contours 30

11. Pressure contours for Mach 5.11

12. Pressure vs radius along various $\mathrm{j}=\mathrm{constant}$ grid lines 32

13. $\mathrm{x}$-t plot for the wave interaction model $\left(\mathrm{H}_{2} \mathrm{O}\right.$ contours with an overlay of 33 pressure)

14. $x-t$ plot for density along the stagnation line 34

15. $\mathrm{x}$-t plot for $\mathrm{H}_{2} \mathrm{O}$ mass-fraction along stagnation line 35

16. $x$-t plot for temperature along stagnation line 36

17. Temporal frequency spectrum of water mass fraction for $101 \times 78$ grid size 37

18. Temporal frequency spectrum of water mass fraction for $131 \times 101$ grid size 38

19. Temporal frequency spectrum of water mass fraction for $197 \times 152$ grid size 39

20. Water mass fraction contours for Mach $6.46 \quad 40$

21. Temperature contours for Mach $6.46 \quad 41$ 


\section{LIST OF SYMBOLS}
$A_{j} \quad$ reaction rate constant for the $j^{\text {th }}$ reaction
$\mathrm{C}_{\mathrm{i}} \quad$ concentation of $\mathrm{i}^{\text {th }}$ species
$\mathrm{C}_{\mathrm{pi}} \quad$ constant pressure specific heat of $\mathrm{i}^{\text {th }}$ species
$\mathrm{D}_{\mathrm{ij}} \quad$ binary diffusion coefficient of $\mathrm{i}^{\text {th }}$ and $\mathrm{j}^{\text {th }}$ species
E total (internal and kinetic) energy
$\epsilon_{\mathrm{j}} \quad$ activation energy of $\mathrm{j}^{\mathrm{th}}$ reaction
$h_{i}{ }^{R} \quad$ base enthalpy of $i^{\text {th }}$ species
k thermal conductivity
$\kappa_{\mathrm{fj}} \quad$ forward rate constant for $\mathrm{j}^{\mathrm{th}}$ reaction
$\kappa_{\text {bj }} \quad$ backward rate constant for $\mathrm{j}^{\text {th }}$ reaction
$\kappa_{\text {eqj }} \quad$ equilibrium constant for $\mathrm{j}^{\text {th }}$ reaction
$\mathrm{M}_{\mathrm{i}} \quad$ molecular weight of $\mathrm{i}^{\text {th }}$ specie
$\mathrm{N}_{\mathrm{s}} \quad$ number of chemical species
$\mathrm{N}_{\mathrm{r}} \quad$ number of chemical reactions
p pressure
$R_{i} \quad$ gas constant of $i^{\text {th }}$ species
T temperature
u $\quad$-component of the velocity
$\tilde{u}_{i} \quad \mathrm{x}$-component of the diffusion velocity of the $\mathrm{i}^{\text {th }}$ component
v $\quad y$-component of the velocity
$\tilde{v}_{i} \quad \mathrm{y}$-component of diffusion velocity of $\mathrm{i}^{\text {th }}$ species
$X_{i} \quad$ mole fraction of $i^{\text {th }}$ species
x streamwise coordinate in the physical 
domain

y normal coordinate in the physical domain

$\alpha_{\mathrm{j}} \quad$ temperature coefficient in reaction rate expression for $\mathrm{j}^{\text {th }}$ reaction

$\Delta G_{R j}$ Gibbs free energy change for the $j^{\text {th }}$ reaction

$\Delta n_{j} \quad$ molar change for the $\mathrm{j}^{\text {th }}$ reaction

$\eta \quad$ normal coordinate in the computational

domain

$\lambda \quad$ second viscosity coefficient

$\mu \quad$ dynamic viscosity

$\nu_{j i}^{\prime} \quad$ stoichiometric coefficient of reactant

corresponding to $i^{\text {th }}$ species and $j^{\text {th }}$ reaction

$\nu_{j i}^{\prime \prime} \quad$ stoichiometric coefficient of product

corresponding to $\mathrm{i}^{\text {th }}$ species and $\mathrm{j}^{\text {th }}$ reaction

$\xi \quad$ streamwise coordinate in the computational

domain

$\rho \quad$ density

$\sigma_{\mathrm{x}} \quad$ normal stress in the $\mathrm{x}$-direction

$\sigma_{\mathrm{y}} \quad$ normal stress in the $\mathrm{y}$-direction

$\tau_{\mathrm{xy}} \quad$ shear stress in the xy plane

$\dot{\omega}_{i} \quad$ production rate of $\mathrm{i}^{\text {th }}$ species 


\section{INTRODUCTION}

The national commitment to the National Aerospace Plane (NASP) program and other hypersonic vehicles such as Trans-Atmospheric Vehicle (TAV) and Aero-assisted Orbital Transfer Vehicle (AOTV) have generated renewed interest in hypersonic flows. Since these vehicles will rely on air-breathing propulsion, hypersonic propulsion is one of the key areas actively researched. For a successful design of the propulsion system to be used for NASP, it is essential to have a clear understanding of the physics of mixing and combustion at supersonic speeds in order to develop efficient engines. In the conventional ramjet engine, free-stream air at high supersonic speeds is compressed to a low subsonic Mach number at the entrance to the combustor. Fuel is injected into the combustor, and burning takes place in a subsonic stream. It is advantageous over the standard gas turbines in the Mach number range of 2 to 5 , but is disadvantageous at hypersonic speeds. Slowing from hypersonic to subsonic speeds will result in large pressure losses and will cause very high temperature of air entering the combustor inlet (much higher than the adiabatic fuel/air flame temperature), resulting in decomposition of the fuel rather than burning. Therefore, the engine will be a drag device rather than a thrust device.

For an efficient propulsion system at hypersonic speeds, the combustion must take place at supersonic speeds, for which two modes of propulsion are being proposed; namely, the Scramjet (supersonic combustion ramjet) and Shramjet (shock-induced combustion ramjet). The Scramjet $([1]-[2])$ is an integrated airframe-propulsion concept for a hypersonic airplane. The entire undersurface of the vehicle is part of the scramjet engine. Initial compression of the air takes place through the bow shock from the nose of the aircraft. Further compression takes place inside a series of modules near the rear of the aircraft, thus increasing its pressure and temperature. In the combustor, fuel (usually hydrogen) is injected into the hot air by a series of parallel and perpendicular injectors where mixing and combustion takes place at supersonic speeds. The expansion of burned gases is partially realized through nozzles in the engine modules but mainly over the bottom rear surface of the aircraft. At high Mach numbers, the fuel and air do not have 
enough time for mixing and, therefore, the combustion efficiency decreases. Thus, in order to get the desired mixing, the length of the combustor has to be long. Since the highest pressure and temperature in the engine occur in the combustor, it has to be very strong; combined with the long length, it increases the weight and the drag of the vehicle.

In order to reduce the size of the combustor, shock-induced combustion (Shramjet [3]) has been proposed, where, a shock is employed to increase the temperature of premixed fuel and air to a point where chemical reaction will start. Apparent advantages of the Shramjet over the Scramjet engine includes very short-length combustors and simple engine geometries. The Shramjet's ability to operate at lower combustor inlet pressures will allow the vehicle to operate at a lower dynamic pressure which lessens the heating loads on the airframe. Up to about Mach 14, Scramjet has better performance than Shramjet, but after that, Shramjet performs better [1].

In the past, many researchers have conducted ballistic range experiments to study the supersonic combustion/detonation. In these experiments, projectiles were fired in different premixed fuel air mixtures, and detonation structures around the projectiles were recorded. Every gas mixture has a detonation wave velocity known as Chapman-Jouget (C-J) velocity, which is characteristic of the mixture. In any reactive gas mixture, if the normal component of the flow velocity following the detonation wave is sonic, then the detonation wave velocity is known as the C-J velocity of the mixture. On the other hand, if the normal component of the flow velocity is subsonic, the detonation wave velocity is called overdriven, and if supersonic, then it is known as underdriven. If the free-stream velocity of the projectile is above the C-J velocity of the reactive mixture, the free stream-velocity is referred to as superdetonative. The detonation wave structure is highly unstable for projectile velocities less than the Chapman-Jouget velocity of the mixture. If the projectile is flying above the C-J velocity of the gas mixture, the detonation or reaction front structure shows a coupled shock-deflagration system near the stagnation line of the body. These two fronts separate from each other as one moves away from the stagnation line. The separation between the two fronts occurs as soon as the velocity component normal to 
the bow shock is equal to the detonation velocity. The separation between the bow shock and the reaction front is called the induction zone. Lehr's [4] experimental ballistic range shadowgraphs for Mach 5.11 and Mach 6.46 are shown in Figs. 1 and 2, respectively. In both cases, a freestream temperature of $292 \mathrm{~K}$ and a pressure of $42663.2 \mathrm{~N} / \mathrm{m}^{2}(320 \mathrm{~mm}$ of $\mathrm{Hg}$ ) is used along with a stoichiometric mixture of hydrogen-air. Fig. 1 shows that the reaction front is separated from the bow shock near the stagnation line, and the instabilities or pulsations in the reaction front are visible for Mach 5.11. Figure 2 is for Mach 6.46 case, and it is seen that the reaction front is coupled with the shock near the stagnation line. A close examination of the shadowgraphs reveals that as the flow crosses the bow shock the color changes from light to dark, indicating an increase in density. But, as the flow crosses the reaction front, the color changes from dark to light, indicating a decrease in density across the reaction front. This is due to a large release of energy across the reaction front, causing an increase in the temperature; since the pressure remains relatively constant, the density must decrease.

Behran et al. [5] conducted similar ballistic range experiments by firing plastic spheres into hydrogen-air mixtures. Similar behavior of transition from stability to instability of the detonation waves was observed when the projectile velocities were decreased to nearly Chapman-Jouget velocity of the mixture.

McVey and Toong [6] also conducted similar experiments where projectiles were fired into lean acetylene-oxygen and stoichiometric hydrogen-air mixtures. They proposed the wave interaction model to explain the instabilities in the structure of the detonation wave. Their model explains how compression waves can be formed when a new reaction front develops in the induction zone between the normal segment of the bow shock and the original reaction front. These compression waves lead to a cyclic process which is compatible with most of the observed features of the flow. However, the strength of the compression waves remained unresolved in their wave-interaction model, which is an important factor in determining if such a model is physically possible. Alpert and Toong [7] included the effect of the strength of the compression 
waves and proposed a modified form of the wave-interaction model.

Several researchers [8-11] have recently attempted to numerically simulate Lehr's ballistic range experiments [4], but have met with limited success. Youngster et al. [8] and Lee and Deiwert [9] simulated Lehr's experimental data for Mach 4.18, 5.11, and 6.46. They used Euler equations coupled with species equations to capture the shock and the reaction front. The reaction model used was hydrogen-air mixture of six species and an inert gas such as Argon or Nitrogen and eight reactions. The flow field was found to be steady in contrast to the experimental evidence that the flow field is, indeed, unsteady. For the test conditions of stoichiometric hydrogen-air mixture, the detonation wave speed of the mixture is Mach 5.11. Experimentally, it has been demonstrated in Lehr's work that Mach 5.11 and 4.18 show structural instabilities of the detonation wave which disappear if the flight Mach number is increased beyond Mach 5.11. Further, the flow field was not well resolved. They used $32 \times 32$ and $57 \times 41$ size grids, respectively, in their blunt body calculations. These grids were not sufficient to resolve the flow field correctly.

Wilson and MacCormack [10] conducted a detailed numerical investigation of the shockinduced combustion phenomena. They used Euler equations and a 13-species and 33-reactions chemistry model. They showed the validity of the reaction models and the importance of grid resolution needed to properly model the flow physics. They did highly resolved calculations for Lehr's Mach 5.11 and Mach 6.46 cases with adaptive grid. The calculations were not time accurate, so that the unsteady behavior was not captured.

Sussman and Wilson [11] also studied the instabilities in the reaction front for a Mach number of 4.79. They also used Euler equations and a 13-species and 33-reactions chemistry model. They have proposed a new formulation based on logarithmic transformation. It greatly reduces the number of grid points needed to properly resolve the reaction front. They successfully simulated the unsteady case. However, the frequency was slightly underpredicted.

Matsuo and Fujiwara [12] have studied the instabilities of shock-induced combustion around 
an axisymmetric blunt body. They used Euler equations and a simplified two-step chemistry model. They investigated the growth of periodic instabilities by a series of simulations with various tip radii and showed that these periodic instabilities are related to shock-standoff distance and induction length. They proposed a new model based on McVey and Toong model [6]. The instabilities in the reaction front were explained by their model.

The instability in the structure of the reaction front originates in the induction zone which separates the bow shock and the exothermic reaction front in the nose region of the flow field and then spreads outwards. In order to capture the physical instabilities, the calculations must be carried out for long times to ensure that all relevant time scales are being captured. Since all numerical schemes have some numerical diffusion, which is dependent on the grid resolution, a coarse grid may damp these oscillations. Further, the numerical damping added to the scheme in the vicinity of the reaction front may damp or alter the instability modes.

The objective of this study is to investigate, in detail, the shock-induced combustion phenomena for the premixed stoichiometric $\mathrm{H}_{2}$-air mixture flow at hypersonic speed (Mach 5.11), which is also the Chapman-Jouget speed of the mixture, past a $15 \mathrm{~mm}$ spherical projectile, including the stability of detonation waves. The analysis is carried out using the axisymmetric version of the SPARK2D code [13], which incorporates a seven-species, seven-reactions combustion model for hydrogen-air mixture. 


\section{BASIC GOVERNING EQUATIONS}

The physical model for analyzing the flow field is described by the Navier-Stokes and species continuity equations. For two-dimensional axisymmetric flows, these equations are expressed in physical coordinates as

$$
\frac{\partial U}{\partial t}+\frac{\partial F}{\partial x}+\frac{\partial G}{\partial y}=H
$$

where vectors $\mathrm{U}, \mathrm{F}, \mathrm{G}$ and $\mathrm{H}$ are written as

$$
U=\left[\begin{array}{c}
\rho \\
\rho u \\
\rho v \\
\rho E \\
\rho f_{i} \\
\cdot \\
\cdot
\end{array}\right]
$$

$$
F=\left[\begin{array}{c}
\rho u \\
\rho u^{2}-\sigma_{x} \\
\rho u v-\tau_{x y} \\
\left(\rho E-\sigma_{x}\right) u-\tau_{x y} v+q_{x} \\
\rho f_{i}\left(u+\tilde{u}_{i}\right) \\
\cdot \\
\cdot
\end{array}\right]
$$

$$
G=\left[\begin{array}{c}
\rho v \\
\rho u v-\tau_{x y} \\
\rho v^{2}-\sigma_{y} \\
\left(\rho E-\sigma_{y}\right) v-\tau_{x y} u+q_{y} \\
\rho f_{i}\left(v+\tilde{v}_{i}\right) \\
\cdot \\
\cdot
\end{array}\right]
$$




$$
H=\frac{1}{y}\left[\begin{array}{c}
\rho v \\
\left(\rho v u+\tau_{x y}\right) \\
\rho v^{2}+\tau_{y y}-\tau_{\theta \theta} \\
\left(\rho E+p+\tau_{y y}\right) v+\tau_{x y} u+q_{y} \\
\omega_{i} \\
\cdot \\
\cdot
\end{array}\right]
$$

The other terms appearing in vectors $F, G$, and $H$ are defined as

$$
\sigma_{x}=-p+2 \mu \frac{\partial u}{\partial x}+\lambda \nabla \cdot u
$$

$$
\sigma_{y}=-p+2 \mu \frac{\partial v}{\partial y}+\lambda \nabla \cdot u
$$

$$
\begin{gathered}
\tau_{x y}=\mu\left[\frac{\partial u}{\partial y}+\frac{\partial v}{\partial x}\right] \\
\tau_{y y}=-\frac{2}{3} \mu\left(2 \frac{\partial v}{\partial y}-\frac{v}{y}-\frac{\partial v}{\partial x}\right) \\
\tau_{\theta \theta}=-\frac{2}{3} \mu\left(2 \frac{v}{y}-\frac{\partial v}{\partial y}-\frac{\partial u}{\partial x}\right)
\end{gathered}
$$

$$
\begin{gathered}
q_{x}=-k \frac{\partial T}{\partial x}+\rho \sum_{i=1}^{N_{s}} h_{i} f_{i} \tilde{u}_{i} \\
q_{y}=-k \frac{\partial T}{\partial y}+\rho \sum_{i=1}^{N_{s}} h_{i} f_{i} \tilde{v}_{i}
\end{gathered}
$$




$$
\begin{gathered}
p=\rho R_{u} T \sum_{i=1}^{N_{s}} \frac{f_{i}}{M_{i}} \\
h_{i}=h_{i}^{R}+\int_{T^{R}}^{T} C_{p_{i}} d T \\
\frac{C_{p_{i}}}{R_{i}}=A_{i}+B_{i} T+C_{i} T^{2}+D_{i} T^{3}+E_{i} T^{4}
\end{gathered}
$$

In Eq. (1) only $\left(\mathrm{N}_{\mathrm{s}}-1\right)$ species equations need to be considered in the formulation since the mass fraction of the species is prescribed by satisfying the constraint equation

$$
\sum_{i=1}^{N_{s}} f_{i}=1
$$

The specific heat at constant pressure for each species is prescribed in Eq. (11) by a fourth-order polynomial in temperature. The multicomponent diffusion equation for the diffusion velocity of the $\mathrm{i}^{\mathrm{th}}$ species

$$
\tilde{u}_{i}=\tilde{u}_{i} i+\tilde{u}_{j} j
$$

is as follows :

$$
\begin{gathered}
\nabla X_{i}=\sum_{j=1}^{N_{s}}\left(\frac{X_{i} X_{j}}{D_{i j}}\right)\left(\tilde{u}_{j}-\tilde{u}_{i}\right)+ \\
\left(\frac{\rho}{p}\right) \sum_{j=1}^{N_{s}} f_{i} f_{j}+\left(f_{i}-X_{i}\right)\left(\frac{\nabla p}{p}\right)+ \\
\sum_{j=1}^{N_{s}}\left(\frac{X_{i} X_{j}}{\rho D_{i j}}\right)\left(\frac{D_{T, j}}{f_{j}}-\frac{D_{T, i}}{f_{i}}\right)\left(\frac{\nabla T}{T}\right)
\end{gathered}
$$

It may be noted that this equation has to be applied only to $\left(\mathrm{N}_{\mathrm{s}}-1\right)$ species. The diffusion velocity for the remaining species is prescribed by satisfying the constraint equation $\sum_{i=1}^{N_{s}} f_{i} \tilde{u}_{i}=0$, which ensures the consistency. In Eq.(7), it is convenient to assume that the body force vector per unit mass is negligible. In addition, thermal diffusion is considered to be negligible when compared with the binary diffusion coefficient. 


\section{CHEMISTRY AND THERMODYNAMIC MODELS}

Chemical reaction rate expressions are usually determined by summing the contributions from each relevant reaction path to obtain the total rate of change of each species. Each path is governed by a law of mass action expression in which the rate constants can be determined from a temperature dependent Arrhenius expression. In vector $\mathrm{H}$, the term $\omega_{i}=M_{i} C_{i}$ represents the net rate of production of species $i$ in all chemical reactions and is modelled as follows :

$$
\begin{gathered}
\sum_{i=1}^{N_{s}} \nu_{j i}^{\prime} S_{i} \rightleftharpoons \sum_{i=1}^{N_{s}} \nu_{j i}^{\prime \prime} S_{i} ; j=1, \ldots N_{r} \\
\omega_{i}=M_{i} \sum_{j=1}^{N_{r}}\left(\nu_{j i}^{\prime \prime}-\nu_{j i}^{\prime}\right)\left[\kappa_{f_{j}} \prod_{m=1}^{N_{s}} C_{m}^{\nu_{j m}^{\prime}}-\kappa_{b_{j}} \prod_{m=1}^{N_{s}} C_{m}^{\nu_{j m}^{\prime \prime}}\right]
\end{gathered}
$$

where Eq.(14) is a representation of an $\mathrm{N}_{\mathrm{r}}$-step chemical reaction, and Eq.(15) is the production rate for the $\mathrm{i}^{\text {th }}$ species as determined from the law of mass action. The reaction constants $\kappa_{\mathrm{fj}}$ and $\kappa_{\text {bj }}$ are calculated from the following equations

$$
\begin{gathered}
\kappa_{f j}=\mathrm{A}_{j} T^{\alpha j} \exp \left(\frac{-\epsilon_{j}}{R_{u} T}\right) ; j=1, \ldots . N_{r} \\
\kappa_{b j}=\frac{\kappa_{f_{j}}}{\kappa_{e q}} ; j=1, \ldots . N_{r}
\end{gathered}
$$

The equilibrium constant appearing in Eq.(18) is given by

$$
\kappa_{e q_{j}}=\left(\frac{1}{R_{u} T}\right)^{\Delta n_{j}} \exp \left(\frac{-\Delta G_{f_{j}}}{R_{u} T}\right) ; j=1, \ldots N_{r}
$$

where

$$
\begin{gathered}
\Delta n_{j}=\sum_{i=1}^{N_{s}} \nu_{j i}^{\prime \prime}-\sum_{i=1}^{N_{s}} \nu_{j i}^{\prime} ; j=1, \ldots N_{r} \\
\Delta G_{R_{j}}=\sum_{i=1}^{N_{s}} \nu_{j i}^{\prime \prime} g_{i}-\sum_{i=1}^{N_{s}} \nu_{j i}^{\prime} g_{i} ; j=1, \ldots N_{r}
\end{gathered}
$$




$$
\begin{gathered}
\frac{g_{i}}{R_{i}}=\mathrm{A}_{i} T(1-\ln T)-\left(\frac{B_{i}}{2}\right) T^{2}-\left(\frac{C_{i}}{6}\right) T^{3} \\
-\left(\frac{D_{i}}{12}\right) T^{4}-\left(\frac{E_{i}}{20}\right) T^{5}+F_{i}-G_{i} T ; i=1, \ldots \ldots N_{s}
\end{gathered}
$$

The forward rate for each reaction is determined from Eq.(17) which is based on the Arrhenius law. The appropriate constants $\mathrm{A}_{j}, \alpha_{j}$, and $\epsilon_{\mathrm{j}}$ for the $\mathrm{H}_{2}$-air reaction system can be found in [14]. The reverse rate is then calculated from Eq.(18). It should be noted that the Gibb's free energy of each species in $\mathrm{g}_{\mathrm{i}}$ is obtained from the expression for $\mathrm{C}_{\mathrm{pi}}$.

The hydrogen-air combustion mechanism used in this work is based on the Jachimowski Hydrogen-air model [14] which uses seven species and seven reactions. The species are $\mathrm{N}_{2}, \mathrm{O}_{2}$, $\mathrm{H}_{2}, \mathrm{OH}, \mathrm{H}_{2} \mathrm{O}, \mathrm{O}$, and $\mathrm{H}$. Each of the seven reactions can proceed in the forward and backward directions. The reactions are

1) $\mathrm{O}_{2}+\mathrm{H}_{2} \rightleftharpoons \mathrm{OH}+\mathrm{OH}$

2) $\mathrm{O}_{2}+\mathrm{H} \rightleftharpoons \mathrm{OH}+\mathrm{O}$

3) $\mathrm{H}_{2}+\mathrm{OH} \rightleftharpoons \mathrm{H}_{2} \mathrm{O}+\mathrm{H}$

4) $\mathrm{H}_{2}+\mathrm{O} \rightleftharpoons \mathrm{OH}+\mathrm{H}$

5) $\mathrm{OH}+\mathrm{OH} \rightleftharpoons \mathrm{H}_{2} \mathrm{O}+\mathrm{O}$

6) $\mathrm{OH}+\mathrm{H}+\mathrm{N}_{2} \rightleftharpoons \mathrm{H}_{2} \mathrm{O}+\mathrm{N}_{2}$

7) $\mathrm{H}+\mathrm{H}+\mathrm{N}_{2} \rightleftharpoons \mathrm{H}_{2}+\mathrm{N}_{2}$

The stoichiometric chemical reaction for a hydrogen-air system can be written as $2 \mathrm{H}_{2}+\mathrm{O}_{2}+3.76 \mathrm{~N}_{2} \longrightarrow 2 \mathrm{H}_{2} \mathrm{O}+3.76 \mathrm{~N}_{2}$

When a blunt body is moving through a reactive mixture at hypersonic speeds, a bow shock is formed ahead of the body, and the temperature of the fuel-air mixture after the bow shock is sufficiently high to initiate the reaction. Once the ignition starts, chemical energy is released and another discontinuity known as reaction front is formed. In the induction zone, the temperature 
and the pressure remain relatively constant at the post shock conditions, while the concentrations of radicals build up very rapidly. 


\section{METHOD OF SOLUTION}

The governing equations are transformed from the physical domain $(x, y)$ to a computational domain $(\xi, \eta)$ using an algebraic grid generation technique. In the computational domain, Eq.

(1) is expressed as

$$
\frac{\partial \hat{U}}{\partial t}+\frac{\partial \hat{F}}{\partial \xi}+\frac{\partial \hat{G}}{\partial \eta}=\hat{H}
$$

where

$$
\begin{gathered}
\hat{U}=U J, \hat{F}=F y_{\eta}-G x_{\eta} \\
\hat{G}=G x_{\xi}-F y_{\xi}, \hat{H}=H J \\
J=x_{\xi} y_{\eta}-y_{\xi} x_{\eta}
\end{gathered}
$$

The governing equations are solved using the MacCormack's [17] method. The scheme is second-order accurate in time and space. This results in a spatially and temporally discrete, simultaneous system of equations at each grid point. The system of equations is solved subject to initial and boundary conditions. At the supersonic inflow boundary, all flow quantities are specified as free-stream conditions. At the supersonic outflow boundary, all flow quantities are extrapolated from interior grid points. Although full N-S equations are used, the slip conditions are used to numerically simulate the inviscid flow. A flow tangency or slip boundary condition is implied on solid wall. The wall temperature and pressure are extrapolated from interior grid points. Initial conditions are obtained by specifying free-stream conditions throughout the flow field. The resulting set of equations is marched in time.

The Lax-Wendroff type schemes are inherently unstable and, hence, higher-order numerical dissipation terms are often necessary to get a stable solution. For a non-reacting flow field, an artificial viscosity based on temperature and /or pressure is traditionally used, but in chemically reacting flows, in addition to temperature and pressure gradients, one can also have very strong species concentration gradients. To suppress the numerical oscillations in the induction zone where the gradients in the concentration of reactants and products are very strong, additional artificial viscosity based on $\mathrm{H}_{2} \mathrm{O}$ mass fraction is used similar to the one used by Singh et al. [15]. 


\section{RESULTS AND DISCUSSIONS}

The stoichiometric chemical reaction for a hydrogen-air system can be written as

$$
2 \mathrm{H}_{2}+\mathrm{O}_{2}+3.76 \mathrm{~N}_{2} \rightarrow 2 \mathrm{H}_{2} \mathrm{O}+3.76 \mathrm{~N}_{2}
$$

When a blunt body is moving through a reactive mixture at hypersonic speeds, a bow shock is formed ahead of the body, and the temperature of the fuel-air mixture after the bow shock is sufficiently high to initiate the reaction. Once the ignition starts, chemical energy is released and another discontinuity known as reaction front is formed. In the induction zone, the temperature and the pressure remain relatively constant at the post shock conditions, while the concentrations of radicals build up very rapidly.

Because of the symmetry, only one half of the flow field is calculated. Figure 3 shows the typical grid which contains $101 \times 78$ grid points (101 normal to the body and 78 along the body). For clarity, every fourth grid point is shown in the figure. For the present case of a stoichiometric hydrogen-air mixture, the Chapman-Jouget velocity is the same as the velocity of the projectile for the Mach 5.11 case. However, for the Mach 6.46 case, the projectile speed is significantly above the detonation velocity of the mixture. Unsteady flow phenomenon can occur if the free-stream velocity of the projectile is around the C-J detonation velocity of the mixture. For both cases, the residuals were dropped by three orders in 12,000 iterations and then remained constant.

Figure 4 shows the contour plot of density for the Mach 5.11 case. The bow shock and the reaction front can be seen clearly in the figure. These are separated from each other by the induction distance. The separation (i.e., the induction distance) is minimum near the stagnation line and increases away from it. This is because near the stagnation line, bow shock is almost normal and, hence, the post shock temperature is maximum; thus, induction distance is minimum. Away from the stagnation line, the shock strength decreases, thereby decreasing the post-shock temperature and, hence, increasing the induction distance. A comparison with Fig. 1 shows that all the flow features are very well captured. Figure 5 shows the corresponding 
plot which has been enlarged for clarity. The bow shock is very crisp and smooth, whereas the reaction front is wrinkled. The pulsations or instabilities which arise at the stagnation point move through the reaction front. The maximum density is seen to be just after the bow shock, and minimum density is after the reaction front. The shock standoff distance is comparable to the Lehr's shadograph. Figure 6 shows the contour plot for temperature, and Fig. 7 shows the corresponding enlarged view. Again, it is seen that the bow shock is very smooth, but the reaction front which separates from the bow shock near the stagnation line shows pulsations. As explained earlier, the post-shock temperature is maximum near the stagnation line and gradually decreases away from it. Also, due to the exothermic nature of the reaction, the temperature further increases as the reaction proceeds. The peak temperature occurs at the stagnation point. Figure 8 shows the temperature along various $j=c o n s t a n t$ grid lines. The post shock stagnation point temperature is $3150^{\circ} \mathrm{K}$, which compares very well with Ref. [10]. As the gas encounters the bow shock, the temperature increases abruptly. Immediately after the shock, the temperature stays constant for a short distance and then begins to increase due to exothermic reactions. The induction zone decreases with increasing temperature, as chemical energy release will be faster for higher temperatures. Also, one can see the unsteadiness in the reaction front. This unsteadiness originates from the induction zone near the stagnation line and then travels downstream. The contour plots for water mass fraction are shown in Figs. 9 and 10. At the end of the combustion zone, the temperature is high enough to start the combustion. As the reaction proceeds, the water mass fraction increases rapidly. The oscillations similar to temperature and density profiles can be seen here. The instability is characterized by an almost regular periodic wave motion having a constant frequency. Similar instability has been observed experimentally in Lehr's work. Figure 11 shows the pressure contour. Again, the bow shock is clearly visible in the figure, and the pressure jump across the shock is comparable with Ref. [9]. Figure 12 shows the line plot for pressure along various $\mathrm{j}=\mathrm{constant}$ grid lines. As the flow crosses the shock, it encounters the pressure jump. The pressure decreases slightly after the shock. The Von Neumann spike, which 
is characteristic of reacting flows, is also visible. The post shock oscillation in pressure along the stagnation line has also been observed in Ref. [9].

The instability in the reaction front has been explained by the wave interaction model as proposed by McVey and Toong [6] and as modified by Matsuo and Fujiwara [11]. Figure 13 shows the wave interaction model in terms of the $x$ - $t$ diagram on the stagnation streamline between the bow shock and the reaction front. The diagram shows the $x-t$ plot for water mass fraction with an overlay of pressure. First, the contact discontinuity approaches the original reaction front. The hot gases behind the contact discontinuity begin to react, generating compression or pressure waves which propagate upstream and downstream. The compression wave which propagates upstream interacts with the bow shock and produces a contact discontinuity behind the bow shock. The hot gases on the contact discontinuity behind the bow shock begin to react, and thus, generating another set of compression waves. At a somewhat later time, the contact discontinuity reaches the position of the original reaction front, extinguishing the reaction at this point because no more unreacted gas exists there, and the rate of energy release is effectively reduced, and thus, generating rarefaction waves. The reaction front begins to recede because of increasing induction time of the colder fluid. The compression wave travelling towards the blunt body gets reflected from the body and travels back to the reaction front and causes a change in the ignition location, and a new pressure wave is created and then the cycle is repeated.

Figure 14 shows the $\mathrm{x}-\mathrm{t}$ plot for density along the stagnation line. The shock front is smooth, but the periodic oscillations of the reaction front are clearly visible. These periodic oscillations are more clear from Fig. 15, which is the $\mathrm{x}-\mathrm{t}$ plot for water mass fraction along the stagnation line. If one sees these oscillations very closely, it will be clear that the water mass production rate, which is also a measure of energy release, continues to increase, and then decreases eventually to zero water mass production and, hence, zero energy release. This is the point of extinguishment of the reaction front. The reaction almost comes to a standstill at this point. Since the new reaction front generated has high energy release (and, hence, high water mass production rate), 
it sends new sets of compression waves, which propagate both upstream and downstream, and the above cycle is repeated. Figure 16 shows the $x-t$ plot for temperature along the stagnation line. The periodic oscillations of the reaction front similar to water mass fraction is noticed.

To further investigate the unsteady nature of the flow field, a Fourier analysis of the flow field was conducted. For this, data at various sample stations along the $j=61$ grid line were stored for 30,000 iterations to get good temporal resolutions. The grid used was $101 \times 78$, and all calculations were time accurate. Figure 17 shows the amplitude vs frequency plot obtained by using Fourier transform. The flow field spectrum is well resolved, and it clearly shows the fundamental frequency of $1.2 \mathrm{e}+6 \mathrm{~Hz}$ and a peak amplitude of 0.004 . It also shows subharmonics and high-frequency numerical noise. Experimental fundamental frequency, as given in Ref. [16], is $1.96 \mathrm{e}+6 \mathrm{~Hz}$. The discrepancies between the experimental and the numerical value could be due to improper grid resolution. The calculations were then repeated for a finer grid $(131 \times 101)$. The grid aspect ratio was kept the same in both the cases. Figure 18 shows the frequency spectrum for the flow field with the finer grid. The sample stations have the same physical locations as in the previous case. The dominant frequency now is $2.0 \mathrm{e}+6 \mathrm{~Hz}$, and the amplitude is 0.004 . This frequency is in close agreement with the experimental value of $1.96 \mathrm{e}+6 \mathrm{~Hz}$. The above calculations were repeated once again for another finer grid of $197 \times 152$. The grid aspect ratio was kept the same and the sample stations have the same physical locations as in the previous cases. Figure 19 shows the frequency spectrum for this grid. The dominant frequency now is $2.1 \mathrm{e}+6 \mathrm{~Hz}$., and the amplitude is 0.004 . Thus, refining the grid has not changed the frequency and therefore, the oscillations in the reaction front are physical.

The results for the Mach 6.46 case will now be presented. As mentioned earlier, this is a superdetonative case, i.e., projectile velocity is higher than the detonation velocity of the mixture.

The temperature contours are shown in Fig. 20. Qualitatively the results are similar to the previous case except near the stagnation zone; the bow shock and the reaction front are now almost coupled due to very small induction distance (because of higher post-shock temperature). 
The two fronts separate from each other slightly downstream.

Figure 21 shows the water mass-fraction contours. Here, in contrast to the previous case, the reaction front is very smooth. The periodic instabilities, which were clearly visible previously, cannot be seen. This is in agreement with the experimental result (see Fig. 2). The frequency spectrum and the stability for Mach 6.46 has not been analyzed in the present study but will be carried on in future work. 


\section{CONCLUSIONS}

A numerical study is carried out to investigate the shock-induced combustion in premixed hydrogen-air mixture. The calculations have been carried out for Mach 5.11 and 6.46. The Mach 5.11 case was found to be unsteady with periodic oscillations. The frequency of oscillations was calculated and was found to be in good agreement with the experimentally observed frequency. The Mach 6.46 case was found to be macroscopically stable, thus supporting the existing view that it is possible to stabilize the shock-induced combustion phenomena with sufficient level of overdrive. 


\section{REFERENCES}

1. Cambier, J. L. and Adelman H., "Numerical Simulations of an Oblique Detonation Wave Engine," AIAA Paper 88-0063, January 1988.

2. White, M. E., Drummond, J. P., and Kumar, Ajay, "Evolution and Status of CFD Techniques for Scramjet Applications," AIAA Paper 86-0160, January 1986.

3. Atamanchuk, T. and Sislian J., "On-And-Off Design Performance Analysis of Hypersonic Detonation Wave Ramjets," AIAA Paper 90-2473, July 1990.

4. Lehr, H. F., "Experiments on Shock-Induced Combustion,"Acta Astronautica, Vol. 17, September 1972, pp. 589-586.

5. Behrens, H., Struth, W., and Wecken F., "Studies of Hypervelocity Firings into Mixtures of Hydrogen with Air or with Oxygen," Tenth Symposium (International) on Combustion, 1965, pp. $245-252$.

6. McVey, J. B. and Toong, T. Y., "Mechanism of Instabilities of Exothermic Hypersonic Blunt-Body Flows," Combustion Science and Technology, Vol. 3, 1971, pp. 63-76.

7. Alpert, L. R. and Toong, T. Y., "Periodicity in Exothermic Hypersonic Flows about Blunt Projectiles," Acta Astronautica, Vol. 17, September 1972, pp. 539-560.

8. Yungster, S., Eberhardt, S., and Bruckner, A. P., "Numerical Simulation of Shock-Induced Combustion by High-Speed Projectiles in Detonable Gas Mixtures," AIAA Paper 89-0673, July 1989.

9. Lee, S. and Deiwert, G. S., " Calculation of Non-equilibrium Hydrogen-Air Reaction with Implicit Flux Vector Splitting Method," AIAA Paper 89-1700, 1989.

10. Wilson, G. J. and MacCormack R. W., "Modelling Supersonic Combustion Using a Fully-Implicit Numerical Method," AIAA Paper 90-2307, July 1990.

11. Sussman, A. M. and Wilson, G. J., "Computation of Chemically Reacting Flow using a Logarithmic form of the Species Conservation Equations," Proceedings of Fourth International 
Conference on Numerical Combustion, Tampa, FL., December 2-4, 1991, pp. 224-227.

12. Matsuo, A. and Fujiwara T., "Numerical Simulations of Shock-Induced Combustion around an Axisymmetric Blunt Body," AIAA Paper 91-1414, June 1991.

13. Drummond, J. P., Rogers, R. C., and Hussaini, M. Y., “A Detailed Numerical Model of a Supersonic Reacting Mixing Layer," AIAA Paper 86-1427, June 1986.

14. Jachimowski, C. J., "An Analytical Study of the Hydrogen-Air Reaction Mechanism with Application to Scramjet Combustion," NASA TP-2791, 1988.

15. Singh, D. J., Carpenter, M. H., and Kumar, A., "Numerical Simulation of Shock-Induced Combustion/Detonation in a Premixed $\mathrm{H}_{2}$-Air Mixture Using Navier-Stokes Equations," AIAA Paper 91-3358, June 1991.

16. Anonymous, Rapport-Bericht $\mathrm{CO} 7 / 73$, Institut Franco-Allenmand De Recherches De Saint-Louis, Kolloquium Uber Gasdetonationen, obgehalten im ISL am 22.10.1973, ISLBeitrage.

17. MacCormack, R. W., "The Effect of Viscosity in Hypervelocity Impact Cratering," AIAA Paper 69-354, April-May 1969. 


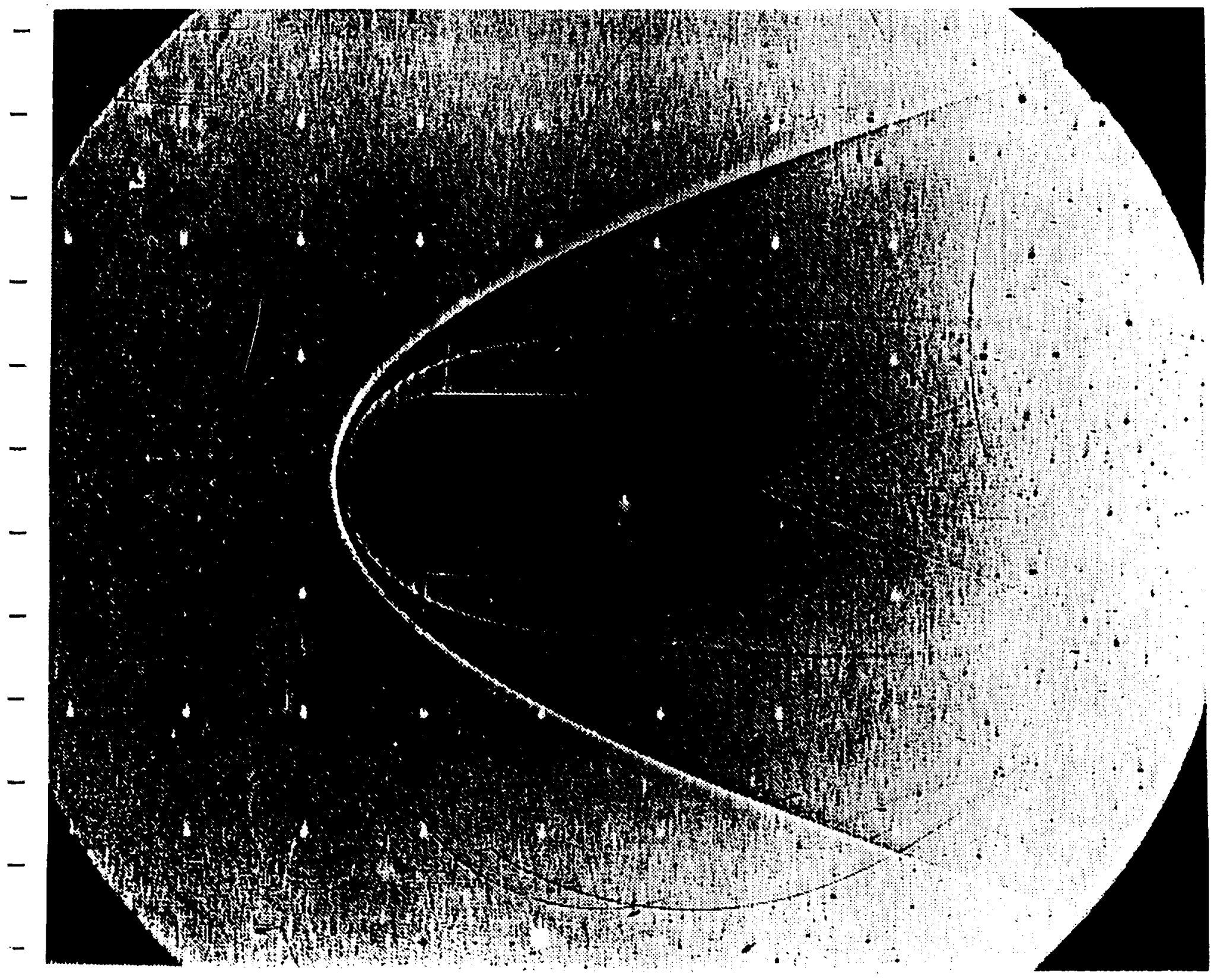

Iigure I Shatoweguaph of a spherical mose projectile moving al Mach 5.11 into a premixed stoichiomenedic hychogen-air mixlune. 


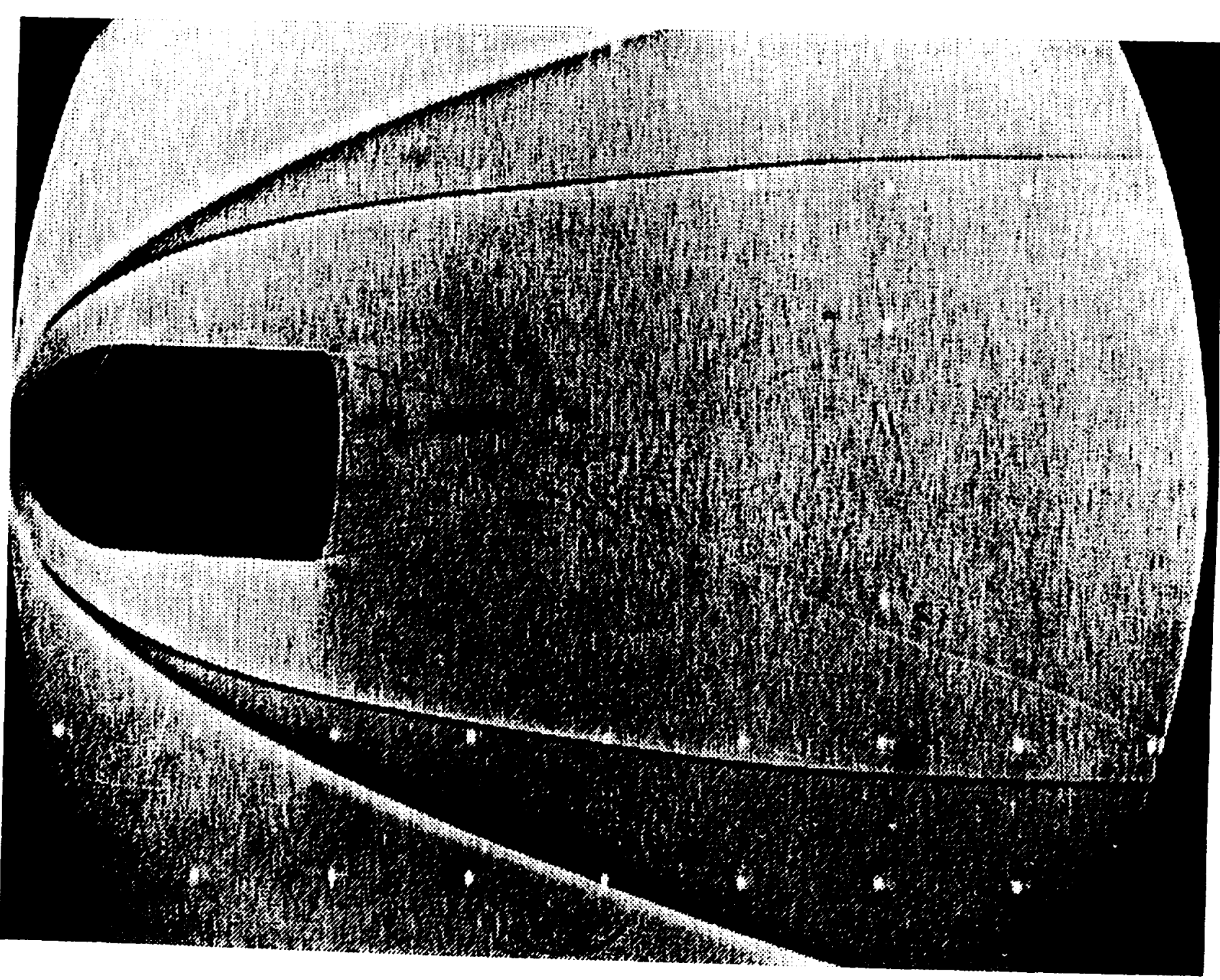

Figure 2 Shadowgraph of a spherical nose projectile moving at Mach 6.46 into a premixed stoichiometric hydrogen-air mixture. 


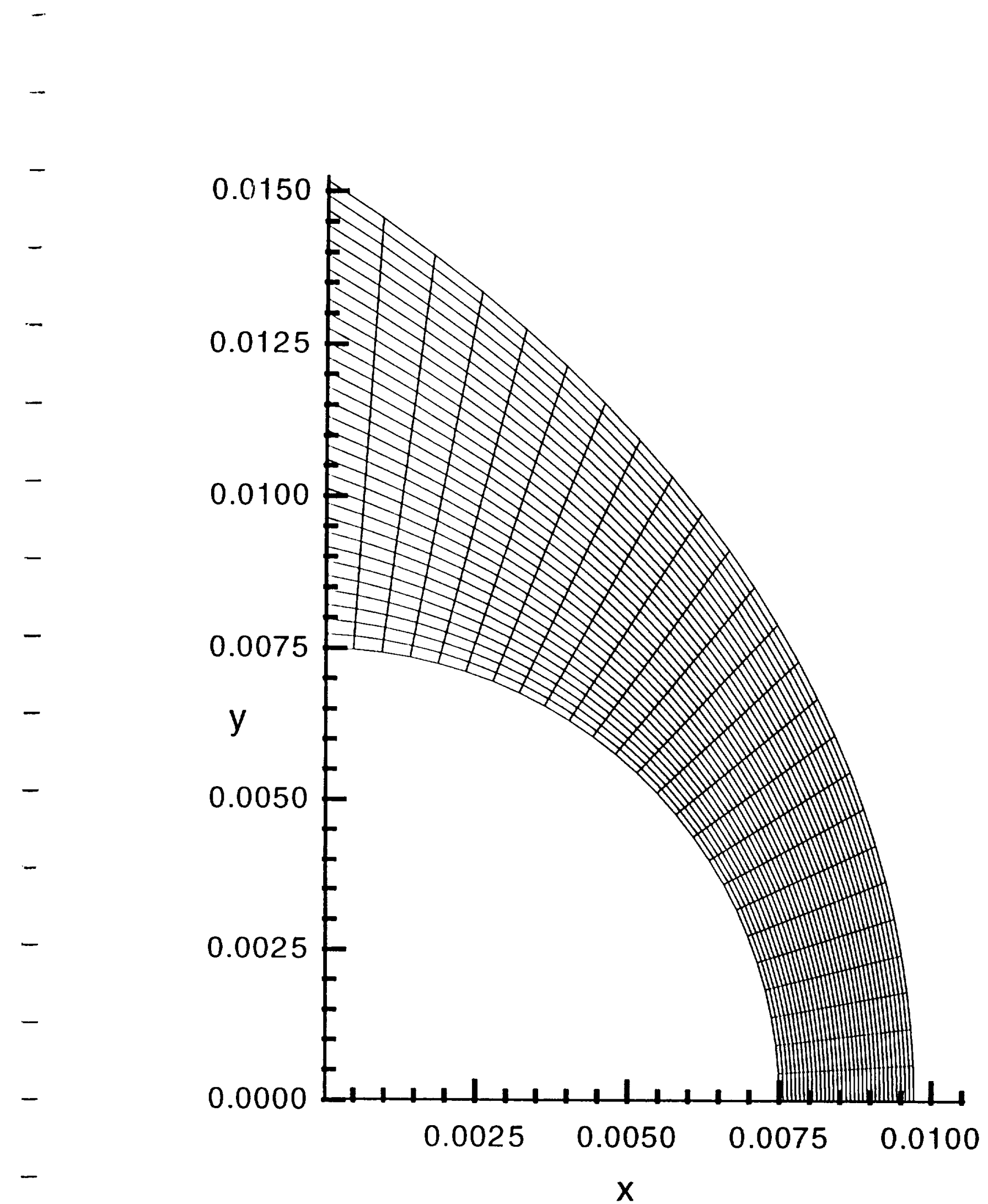

Figure 3 Typical grid for the calculation 


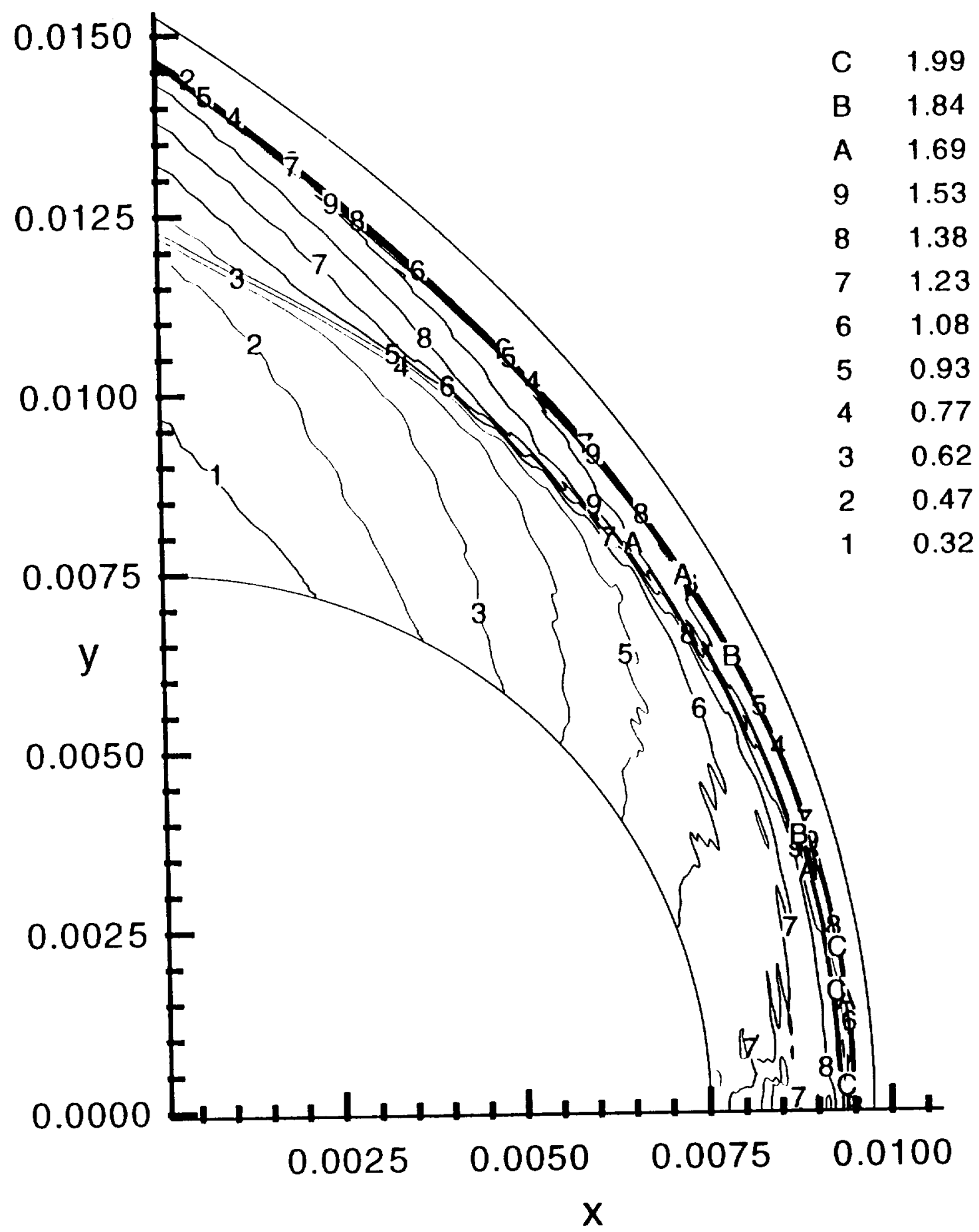

Figure 4 1)ensity contours for Mach 5.11 


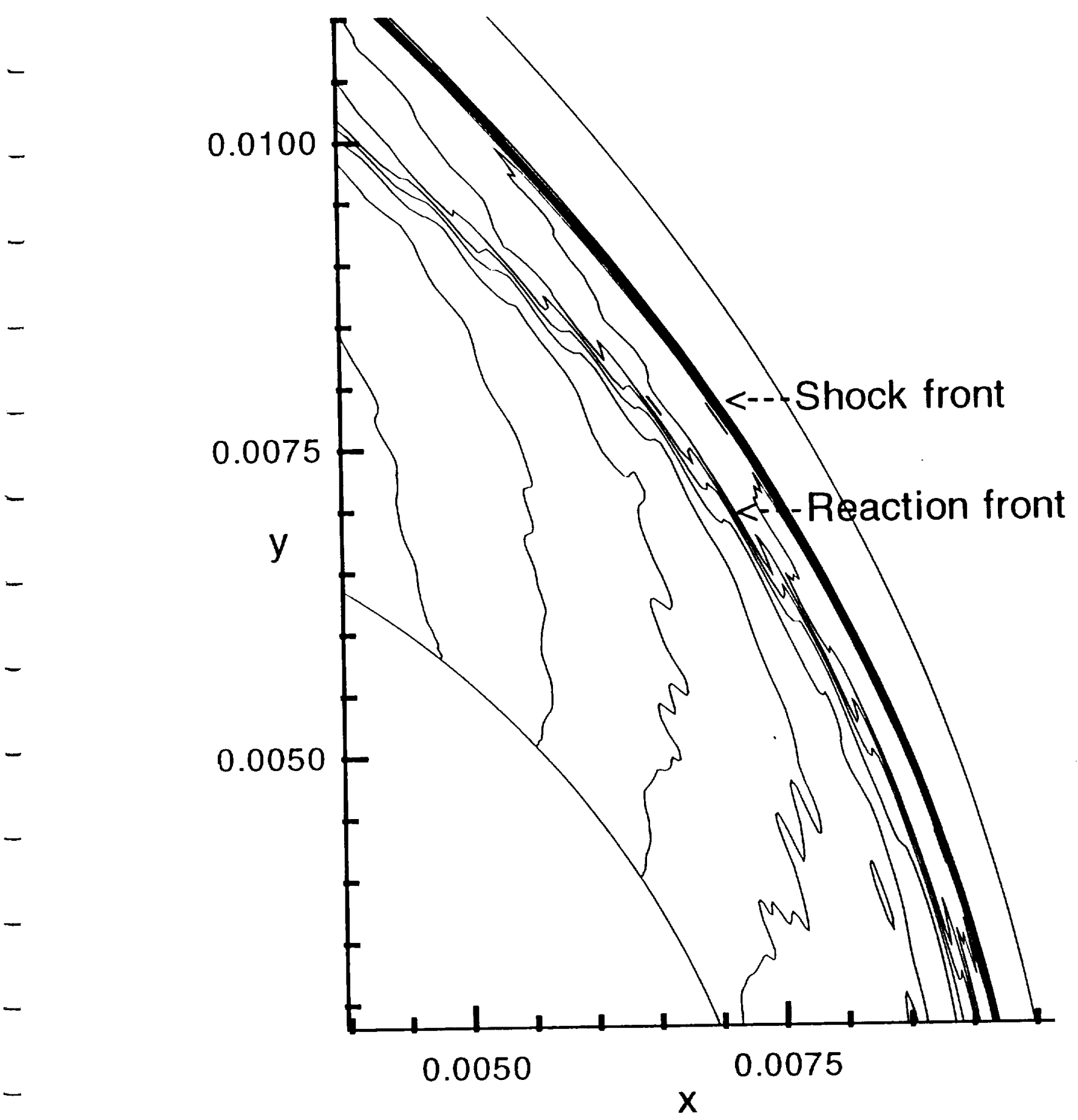

Figure 5 Enlarged view of density contours for Mach 5.11 


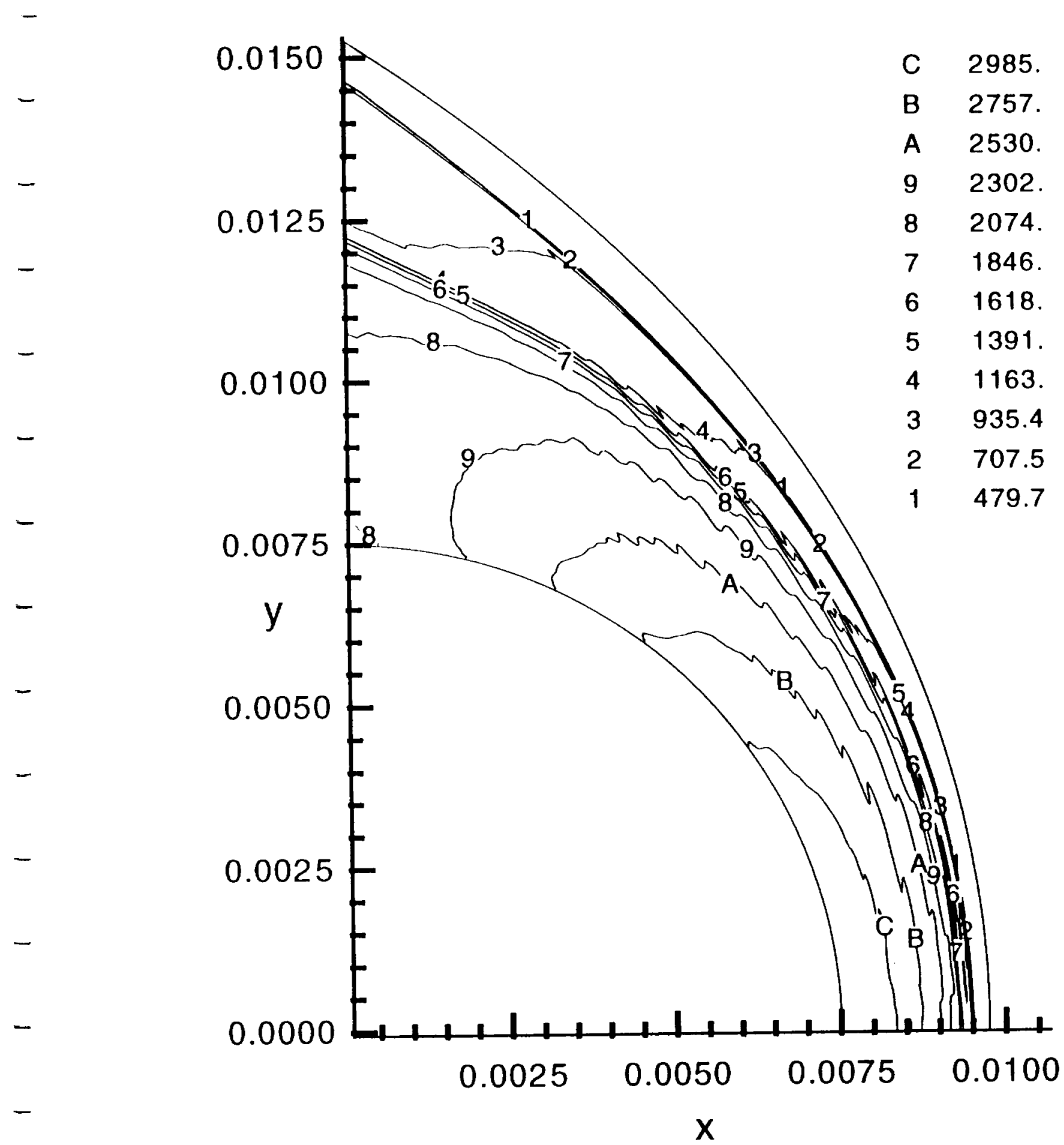

Figure 6 Temperature contours for Mach 5.11 


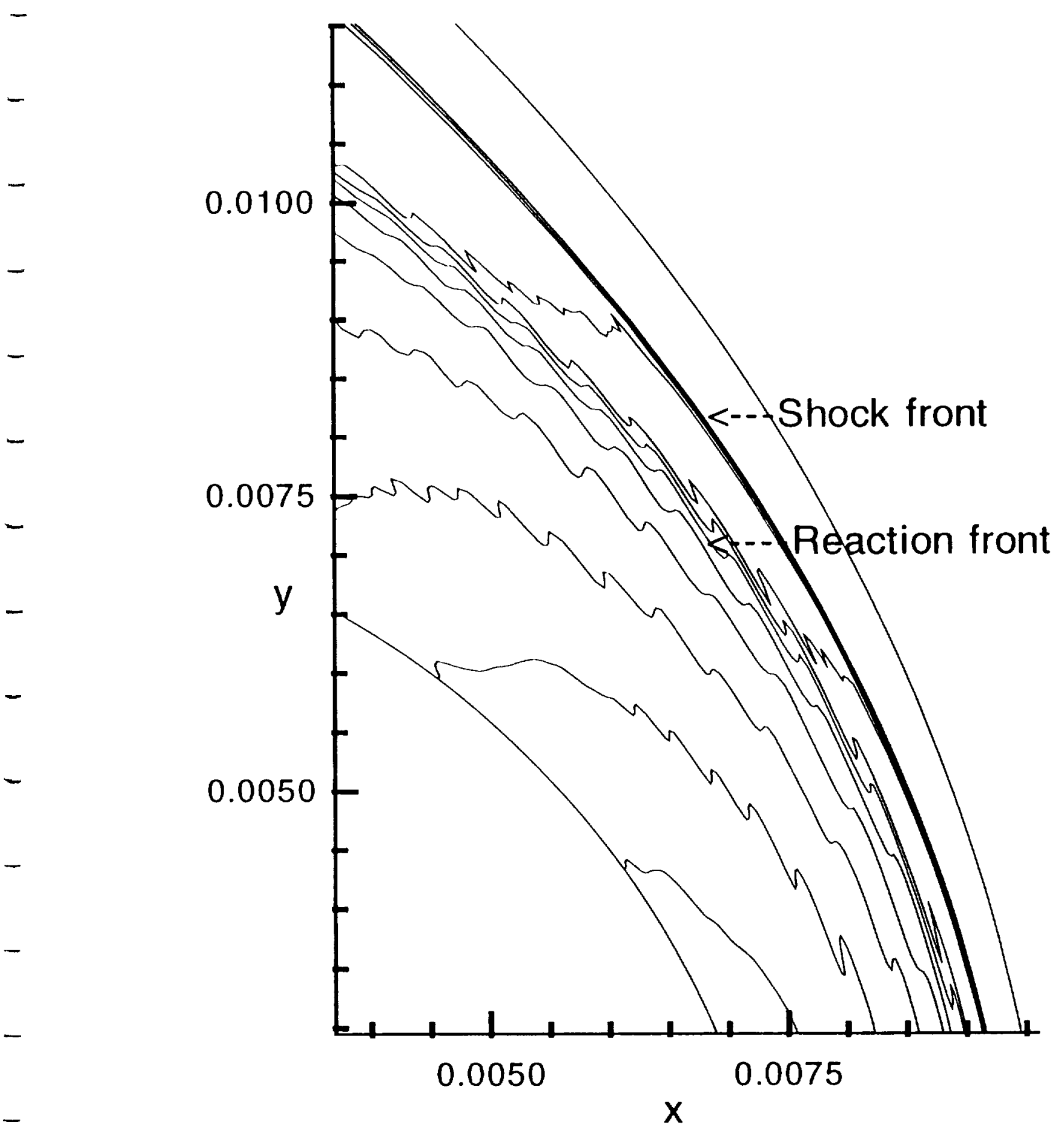

Figure 7 Enlarged view of lemperature contour for Mach 5.11 


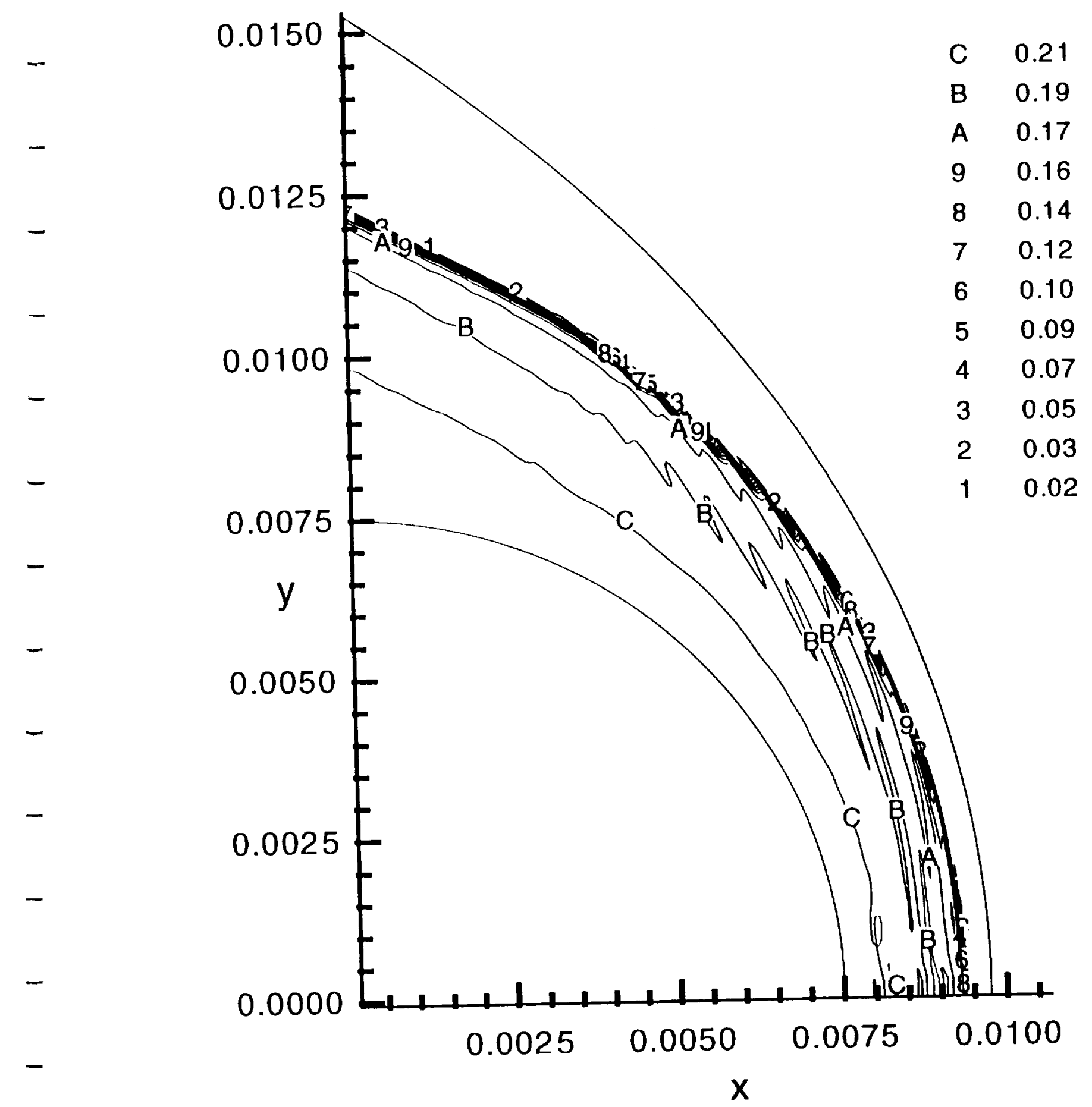

Figure 9 Water mass fraction contours for Mach 5.11 


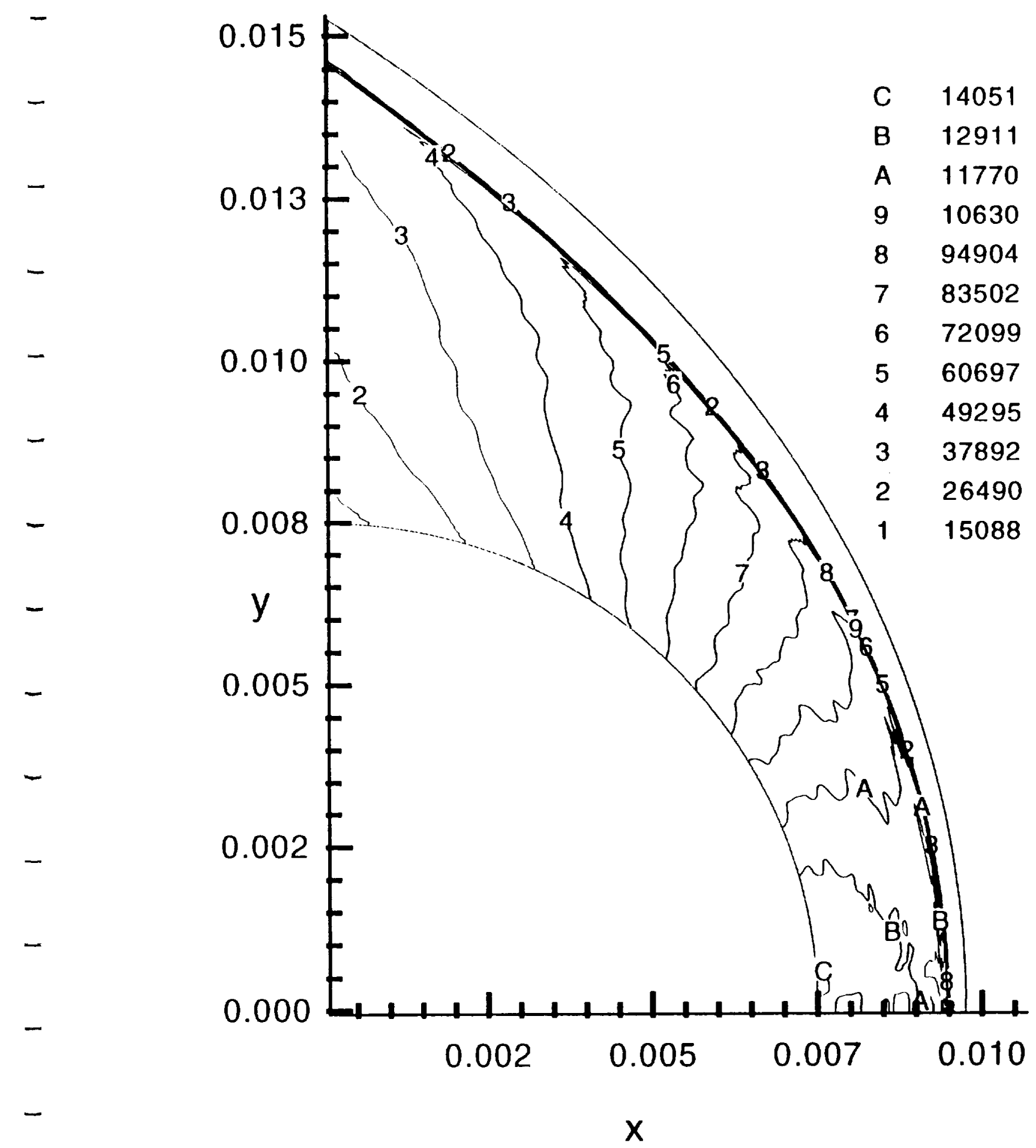

Figure II Pressure contours for Mach 5.11 


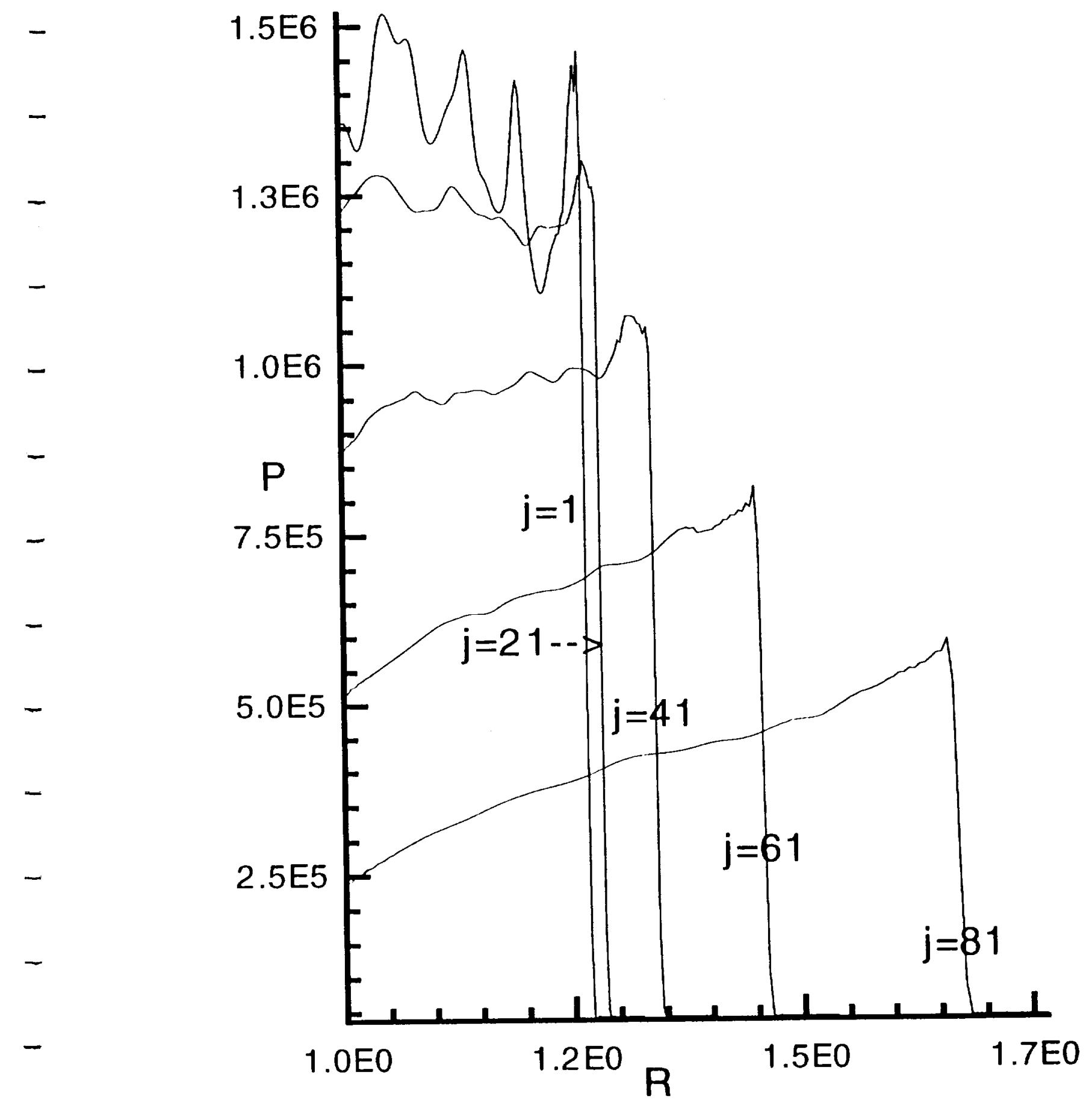

Figure 12 Pressure vs radius along various $j=$ constant grid lines 


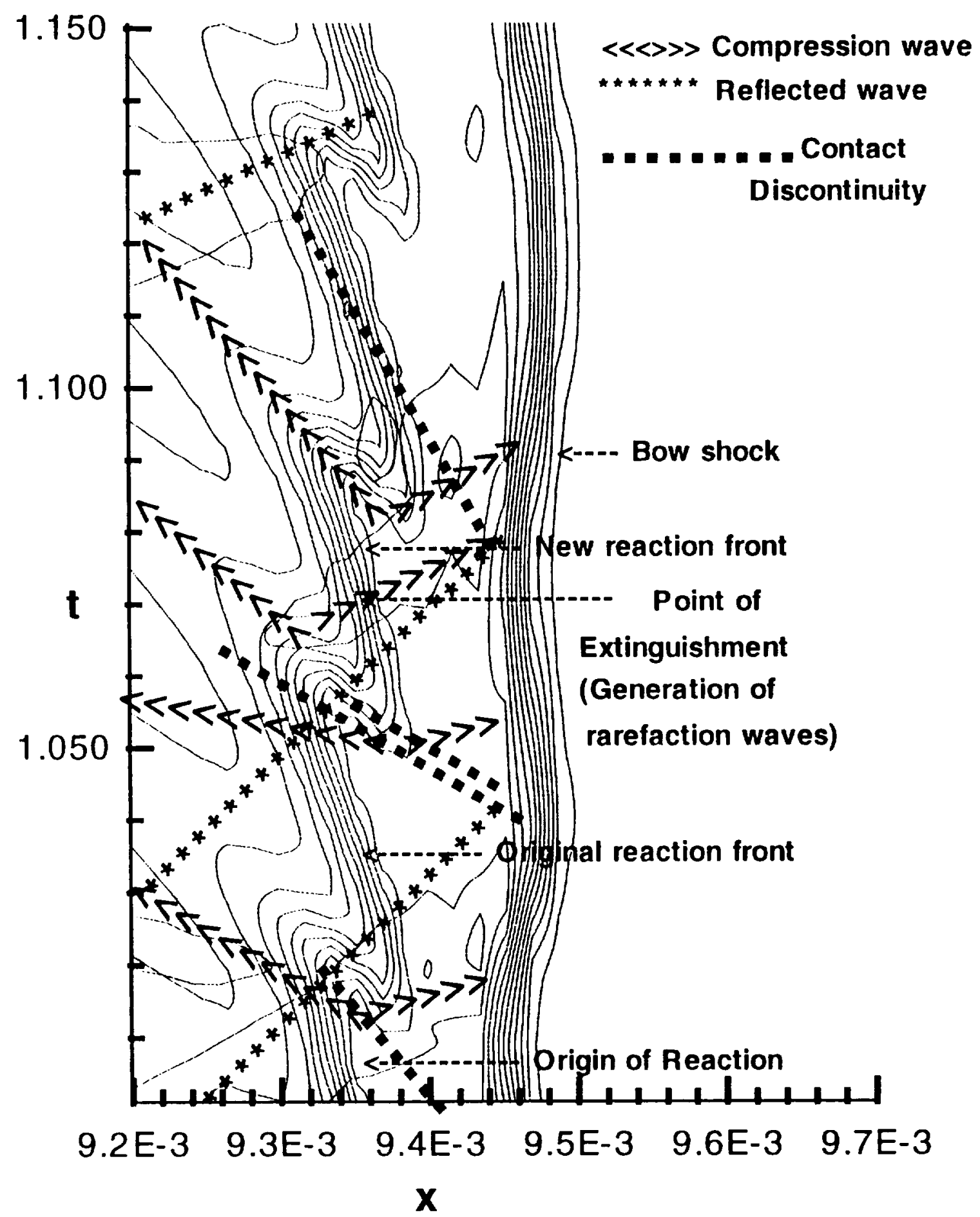

Figure $13 x-1$ plot for the wave interaction model $\left(\mathrm{H}_{2} \mathrm{O}\right.$ contours with an overlay of pressure) 


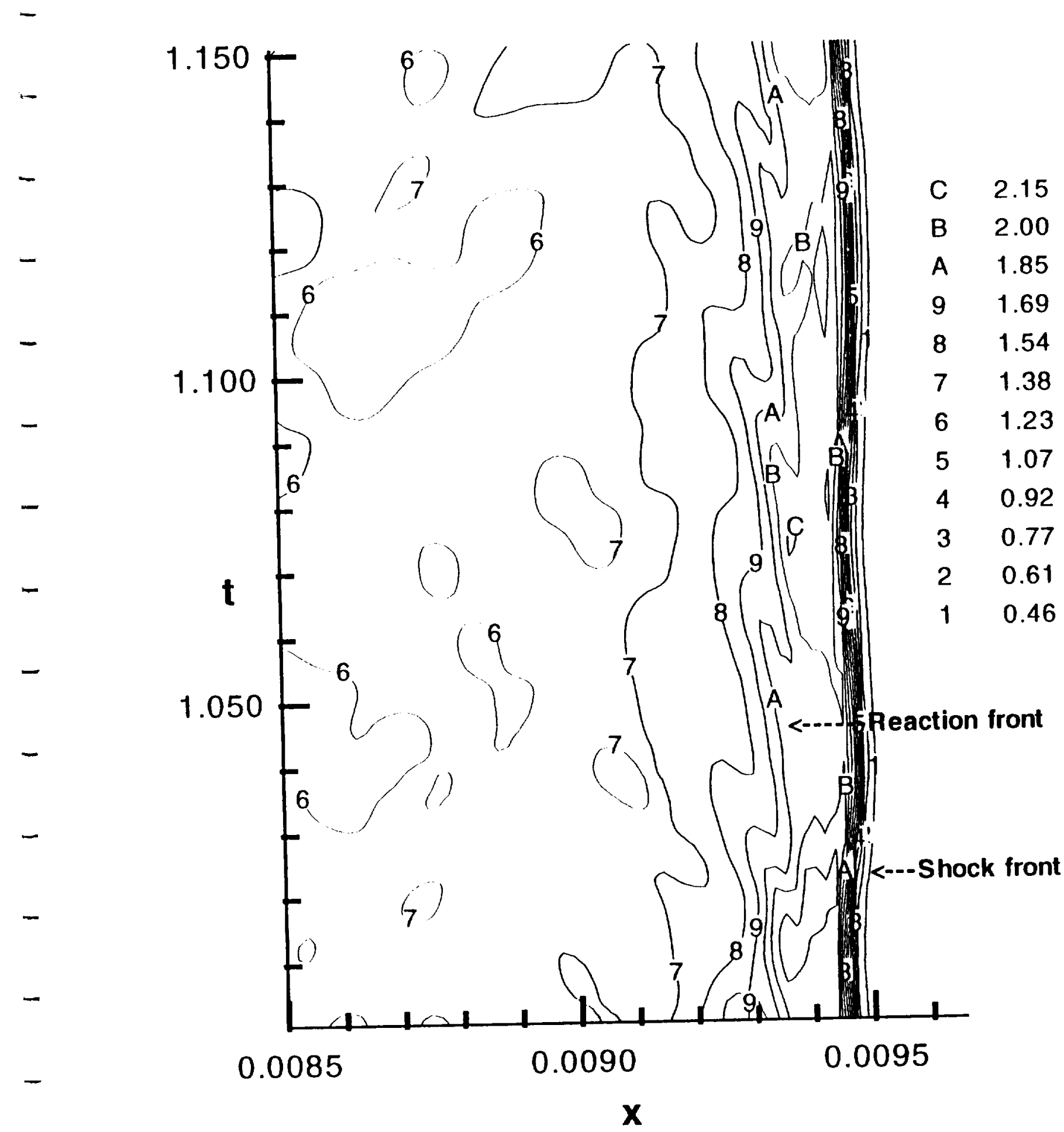

Figure $14 \times-1$ plot for density along the stagnation line 


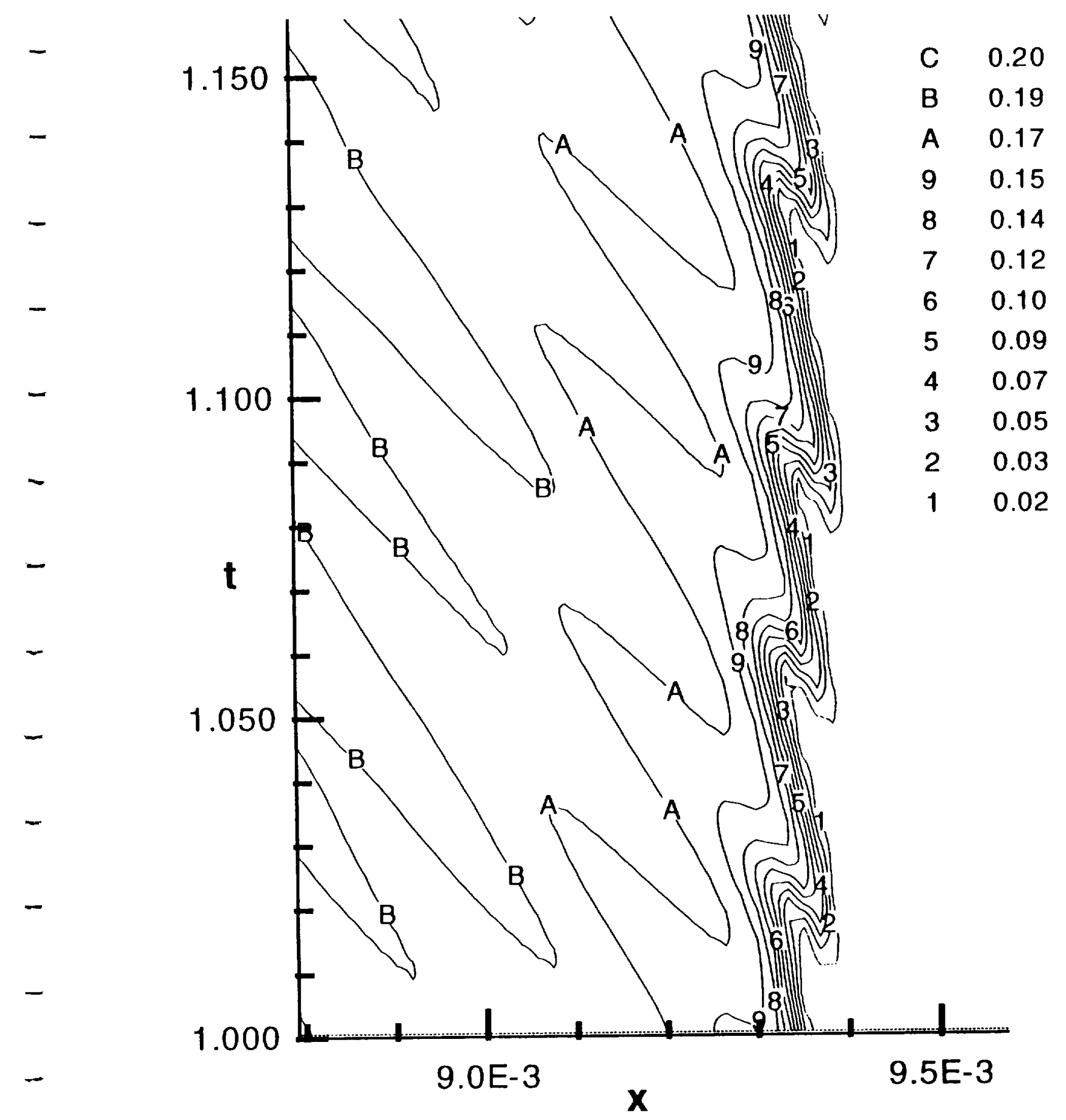

Figure $15 \times-t$ plot for $1 \mathrm{H}_{2} \mathrm{O}$ ) mass-fraction along stagnation line 


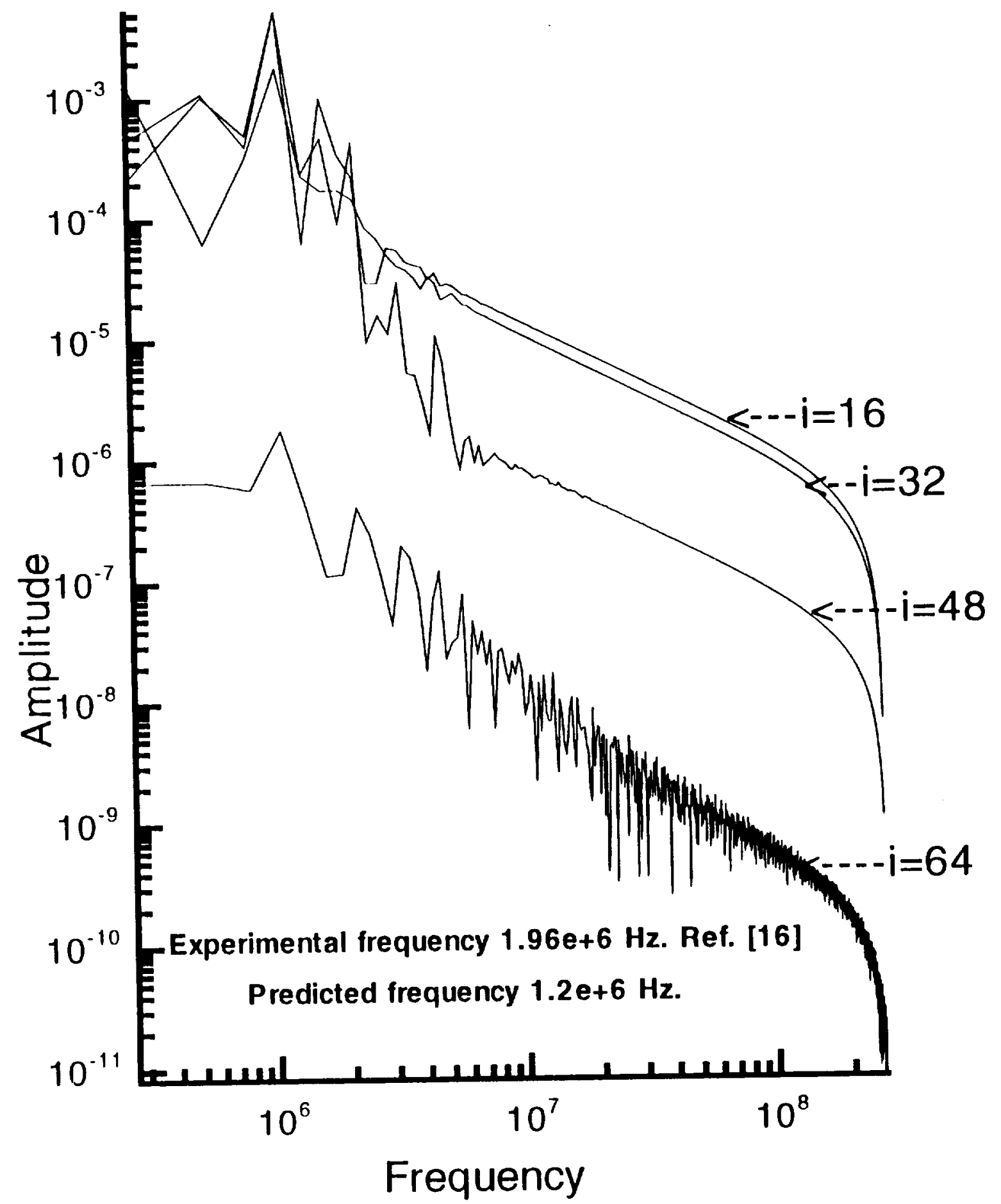

Figure 17 Temporal frectuency spectrum of water mass fraction for $101 \times 78$ grid sizc. 


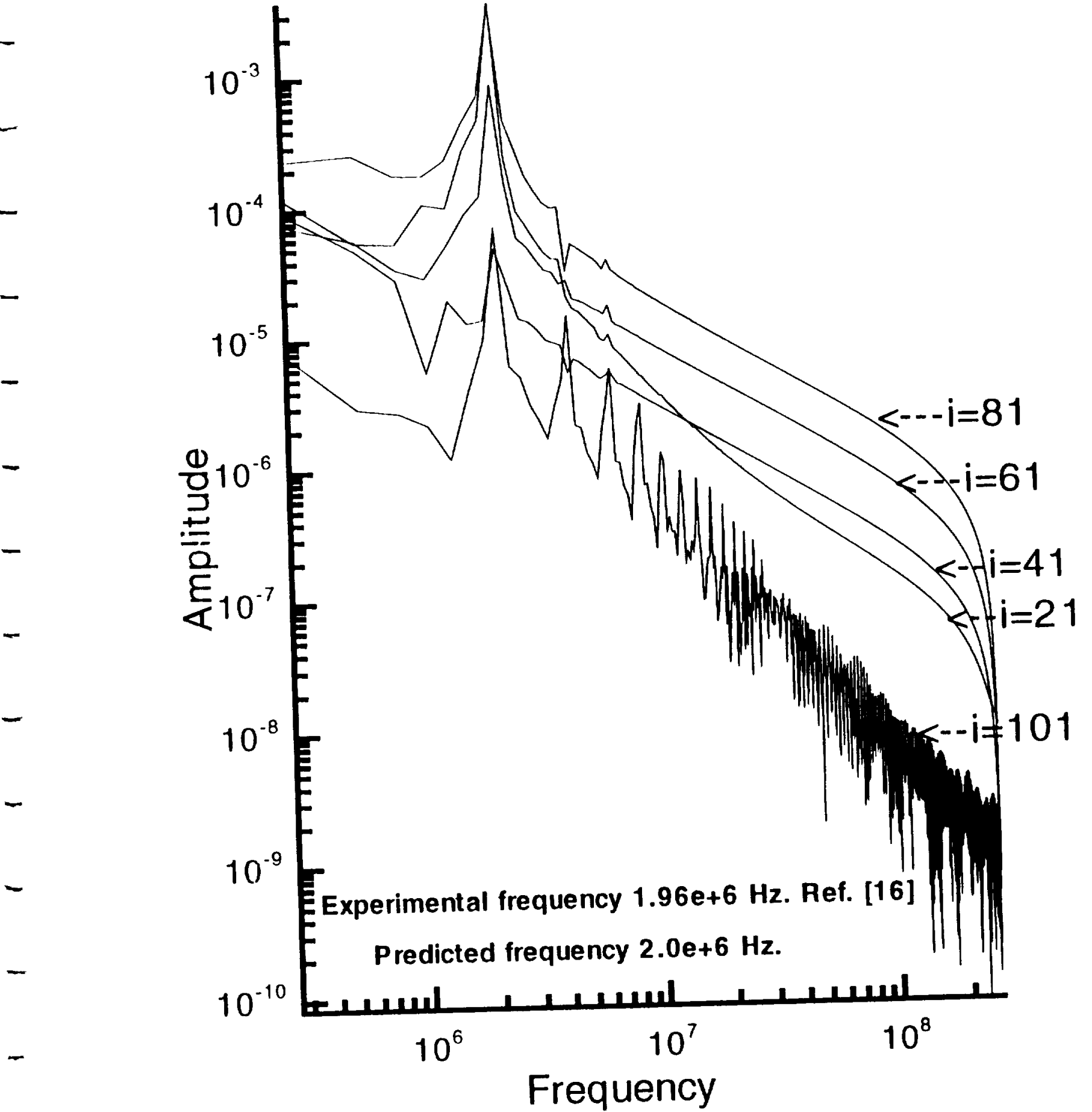

Figure 18 Temporal frepuency spectrum of water mass fraction for $131 \times 101$ grid size. 


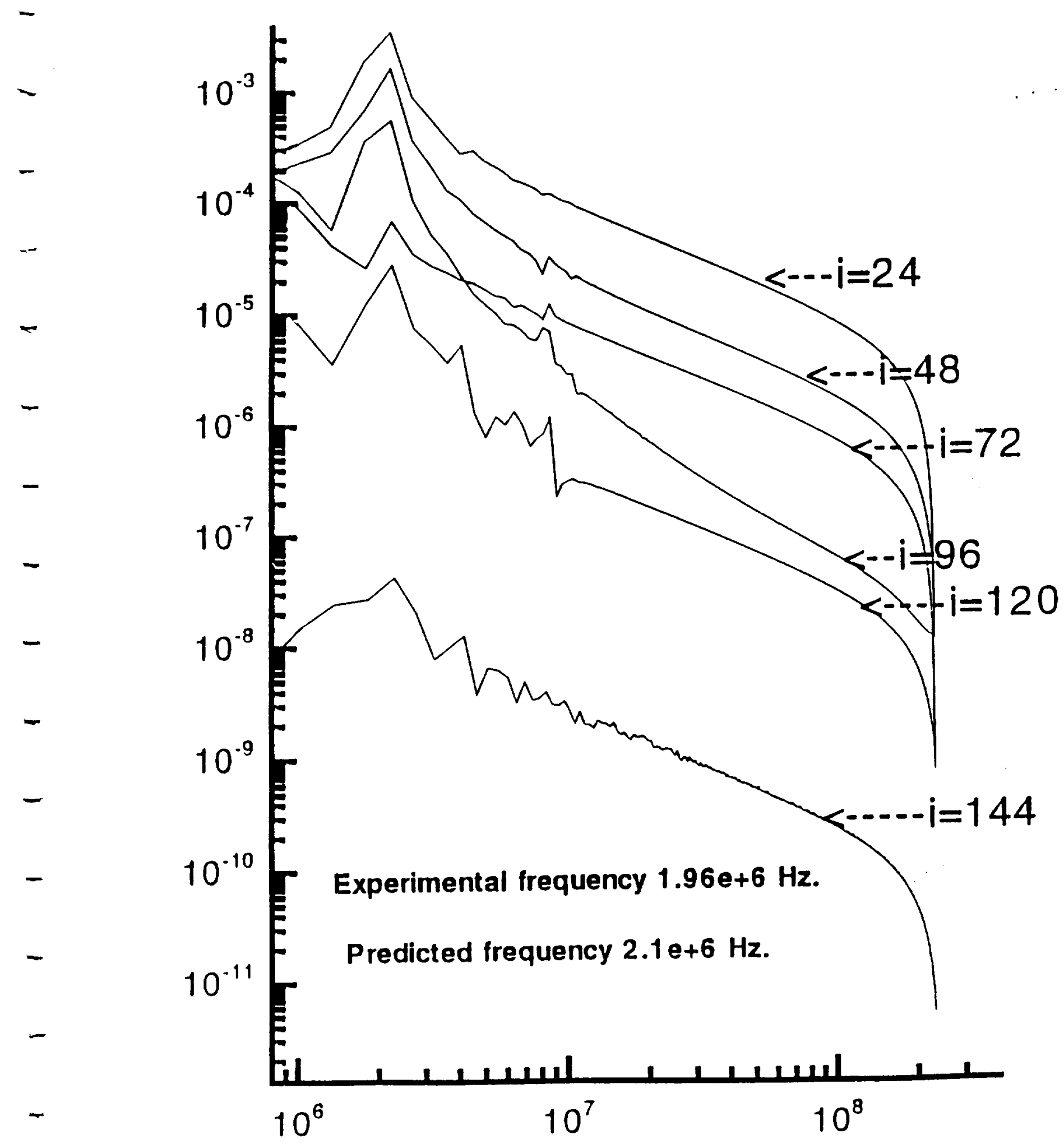

Figure 19 Tempotal frequency spectrum of water mass fraction for $197 \times 1.52$ grid size. 

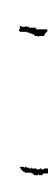

-

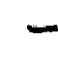

$-$

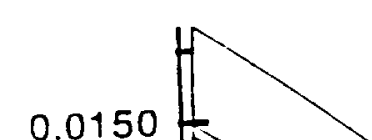

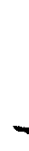

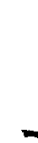
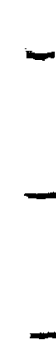

Figure 20) Temperature contours for Mach 6.46 


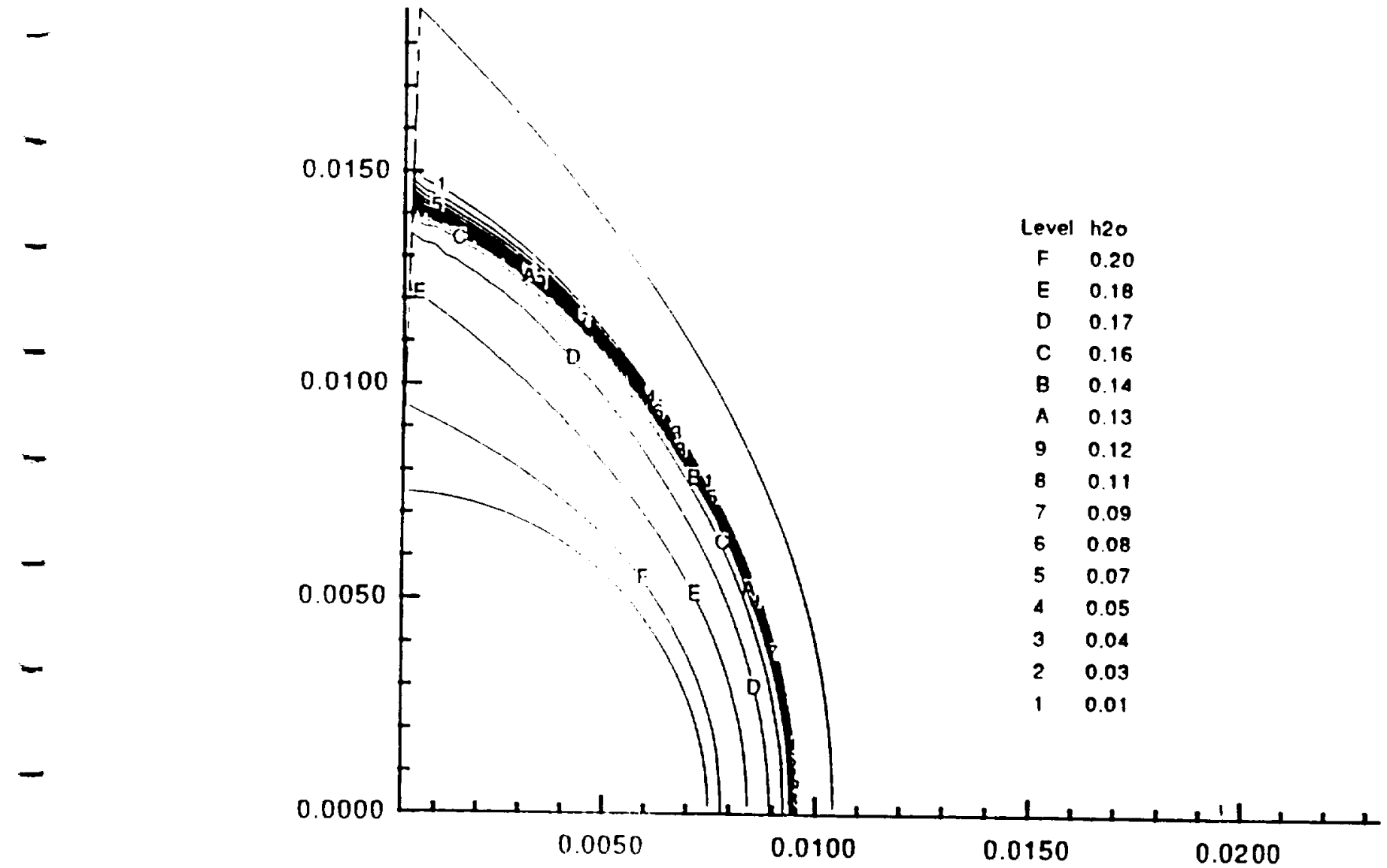

Figure 21 Wille mass liaclion contours for Mach 6.46 


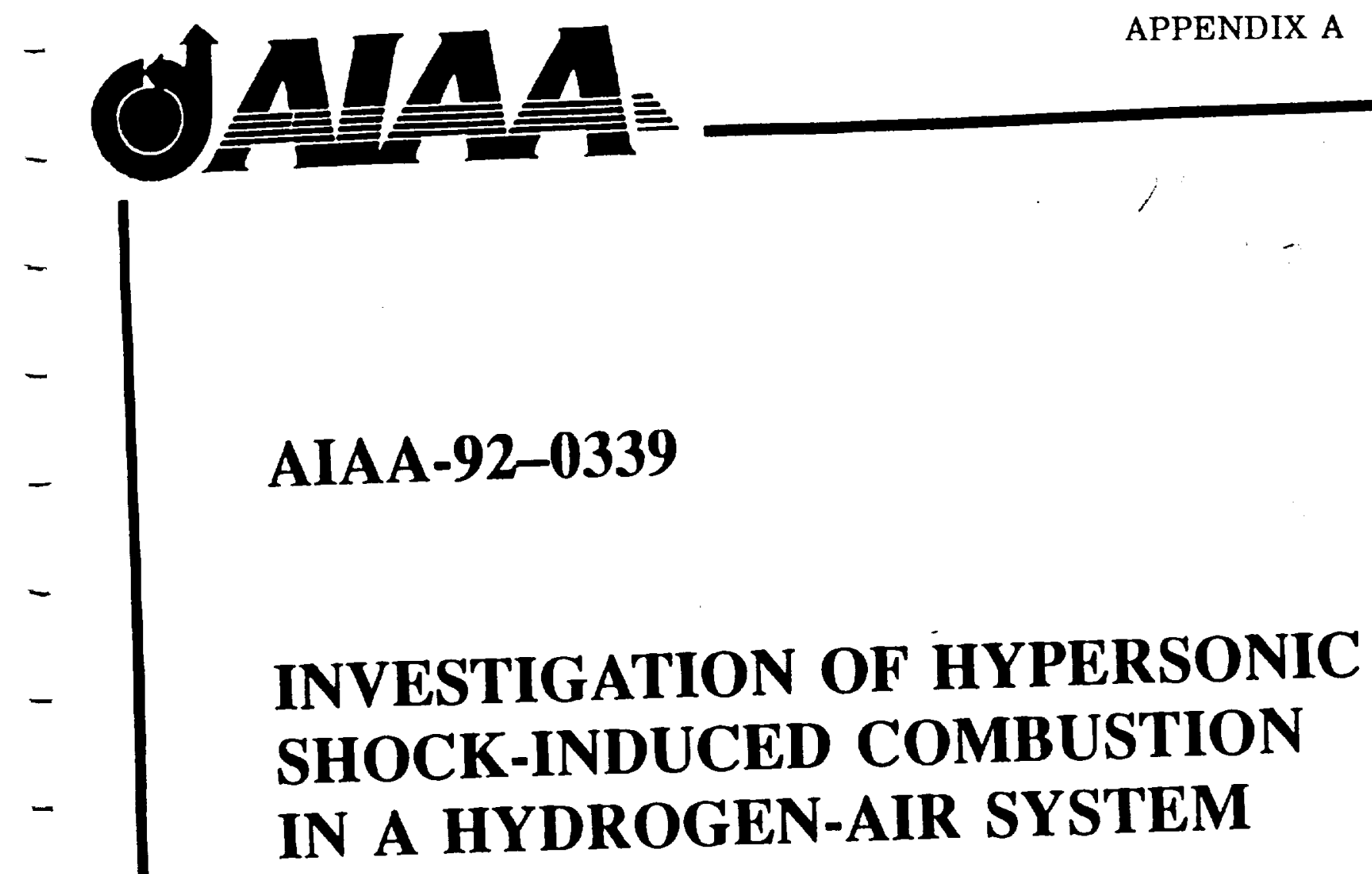

J. K. Ahuja

Old Dominion University, Norfolk, VA 23508

S. N. Tiwari

Old Dominion University, Norfolk, VA 23508

D. J. Singh

Analytical Services and Materials Inc.,

Hampton, VA 23666

\section{0th Aerospace Sciences Meeting \& Exhibit \\ January 6-9, 1992 / Reno, NV}




\title{
INVESTIGATION OF HYPERSONIC SHOCK-INDUCED COMBUSTION IN A HYDROGEN-AIR SYSTEM
}

\author{
J. K. Ahuja* \\ Old Dominion University, Norfolk, VA 23508 \\ S. N. Tiwari ${ }^{\dagger}$ \\ Old Dominion University, Norfolk, VA 23508 \\ J. J. Singh ${ }^{\ddagger}$
}

Analytical Services and Materials Inc., Hampton, VA 23666

\begin{abstract}
$A$ numerical study is conducted to simulate the ballistic range experiments at Mach 5.11 and 6.46. The flow ficld is found to be unsteady with periodic instahilities originating in the stagnation zone. The unsteadiness of the flow field decreased with increase in Mach number, thus indicating that it is possible to stabilize such flow fields with a high degrec of overdrive. The frequency of periodic instability is determined using Fourier power spectrum and is found to he in good agreement with the experimental data. The physics of the instability are explained by the wave interaction model as proposed earlier by McVey et al. and subsequently modified hy Matsuo et al.
\end{abstract}

\section{NOMENCLATURE}

$\Lambda_{j} \quad$ reaction rate constant for the $\mathrm{j}^{\text {th }}$ reaction

$C_{i} \quad$ concentation of $i^{\text {th }}$ species

$\mathrm{C}_{\mathrm{pi}} \quad$ constant pressure specific heat of $\mathrm{i}^{\text {th }}$ species.

$D_{i j} \quad$ hinary diffusion coeflicient of $i^{\text {th }}$ and $j^{\text {th }}$ species.

E total (internal and kinetic) energy

$\epsilon_{j} \quad$ activation energy of $j^{\text {tht }}$ reaction

$h_{i}{ }^{R} \quad$ base enthalpy of $i^{\text {th }}$ species

$k$ thermal conductivity

$\kappa_{i j} \quad$ forward rate constant for $j^{\text {th }}$ reaction

$\kappa_{\text {hj }} \quad$ hackward rate constant for $j^{\text {th }}$ reaction

$\kappa_{\text {ecuj }}$ equilibrium constant for $\mathrm{j}^{\text {th }}$ reaction

$\mathrm{M}_{\mathrm{i}} \quad$ molccular weight of $\mathrm{i}^{\text {th }}$ specie

$\mathrm{N}_{\mathrm{s}} \quad$ number of chemical species

$\mathrm{N}_{\mathrm{r}} \quad$ number of chemical reactions

$\mathrm{P}$ pressure

$R_{i} \quad$ gas constant of $i^{\prime \prime \prime}$ species

$\mathrm{T}$ temperature

"I $\quad x$-component of the velocity

$\bar{u}_{i} \quad \mathrm{x}$-component of the diffusion velocity of the $i^{\text {th }}$ component

$v \quad y$-component of the velocity

Ciraduate Research Assisıant, AIA

Eminent Professor, AIA A Associate Fellow

Rescarch Scientist, AIA Member

This paper is declared a work of the U.S. Ginvernment and is not sulpject to copyrigla protection in the (Inited States. $\tilde{v}_{i} \quad y$-component of diffusion velocity of $\mathrm{j}^{\text {th }}$ species

$X_{i} \quad$ mole fraction of $i^{\text {th }}$ species

$x \quad$ streamwise coordinate in the physical domain

$y$ normal coordinate in the physical domain

$\alpha_{j}$ temperature coefficient in reaction rate expression for $j^{\text {th }}$ reaction

$\Delta G_{R j}$ Gibhs free energy change for the $j^{\text {th }}$ reaction

$\Delta n_{j} \quad$ molar change for the $j^{\text {th }}$ reaction

$\eta \quad$ normal coordinate in the computational domain

$\lambda \quad$ second viscosity coefficient

$\mu$ dynamic viscosity

$v_{j i}^{\prime} \quad$ stoichiometric coefficient of reactant corresponding to $i^{\text {th }}$ species and $j^{\text {th }}$ reaction

$\nu_{j i}^{\prime \prime} \quad$ stoichiometric coefficient of product corresponding to $\mathrm{i}^{\text {th }}$ species and $\mathrm{f}^{\text {th }}$ reaction

$\xi \quad$ stream wise coordinate in the computational domain

$\rho$ density

$\sigma_{\mathrm{x}} \quad$ normal stress in the $\mathrm{x}$-direction

$\sigma_{y} \quad$ normal stress in the $y$-direction

$\tau_{x y} \quad$ shear stress in the $x y$ plane

$\dot{\omega}_{i} \quad$ production rate of $i^{\text {th }}$ species

\section{INTRODUCTION}

The national commitment to the National Aerospace Plane (NASP) program and other hypersonic vehicles such as Trans-Atmospheric Vehicle (TAV) and Aeroassisted Orbital Transfer Vehicle (AOTV) have generated renewed interest in hypersonic flows. Since these vehicles will rely on air-breathing propulsion, hypersonic propulsion is one of the key areas actively researched. For a successful design of the propulsion system to be used for NASP, it is essential to have a clear understanding of the physics of mixing and combustion at supersonic speeds in order to develop efficient engines. In the conventional ramjet engine, free-stream air at high supersonic speeds is compressed to a low subsonic Mach number at the entrance to the combustor. Fuel is injected into the combustor, and burning takes place in a suhsonic stream. It is advantageous 
over the standard gas turbines in the Mach number range of 2 to 5 , but is disadvantageous at hypersonic speeds. Slowing from hypersonic to subsonic speeds will result in large pressure losses and will cause very high temperature of air entering the combustor inlet (much higher than the adiabatic fuel/air flame temperature), resulting in decomposition of the fuel rather than burning. Therefore, the engine will be a drag device rather than a thrust device.

For an efficient propulsion system at hypersonic speeds, the combustion must lake place at supersonic speeds, for which two modes of propulsion are being proposed; namely, the Scramjet (supersonic combustion ramjet) and Shranjet (shock-induced combustion ramjet). The Scramjet $([1]-[2])$ is an integrated airframe-propulsion concept for a hypersonic airplane. The entire undersurface of the vehicle is part of the scramjet engine. Initial compression of the air takes place through the bow shock from the nose of the aircraft. Further compression takes place inside a series of modules near the rear of the aircraft, thus increasing its pressure and temperature. In the combustor, fuel (usually hydrogen) is injected into the hot air by a series of parallel and perpendicular injectors where mixing and combustion takes place at supersonic speeds. The expansion of burned gases is partially realized through nozzles in the engine modules but mainly over the bottom rear surface of the aircratt. At high Mach $10 u m$ bers, the fuel and air do not have enough time for mixing and, therefore, the combustion efficiency decreases. Thus, in order to get the desired mixing, the length of the combustor has to be long. Since the highest pressure and temperature in the engine occur in the combustor, it has to be very strong; combined with the long length, it increases the weight and the drag of the vehicle.

In order to reduce the size of the combustor, shock-induced combustion (Shramjet [3]) has been proposed, where, a shock is employed to increase the temperature of premixed fuel and air to a point where chemical reaction will start. Apparent advantages of the Shramjet over the Scramjet engine includes very short-length combustors and simple engine geometries. The Shramjet's ability to operate at lower combustor inlet pressures will allow the vehicle to operate at a lower dynamic pressure which lessens the heating loads on the airtrame. Up to about Mach 14, Scramijet has better performance than Shramjet, but atter that, Shramjet performs better [1].

In the past, many researchers have conducted ballistic range experiments to study the supersonic conbustion/detonation. In these experiments, projectiles were fired in different premixed fuel air mixtures, and detonation structures around the projectiles were recorded. Every gas mixture has a detonation wave velocity known as Chapman-Jouget (C-J) velocity, which is characteristic of the mixture. In ally reactive gas mixture, if the normal component of the flow velocity following the detonation wave is sonic, then the detonation wave velocity is known as the $\mathrm{C}$-J velocity of the mixture. On the other hand, if the normal component of the flow velocity is subsonic, the detonation wave velocity is called overdriven, and if supersonic, then it is known as underdriven. If the frce-stream velocity of the projectile is above the $C$-J velocity of the reactive mixture, the free stream-velocity is relerred to as superdetonative. The detonation wave structure is highly unstable for projectile velocities less than the Chapman-Jouget velocity of the mixture. If the projectile is flying above the $C-J$ velocity of the gas mixture, the detonation or reaction front stnucture shows a coupled shock-detlagration system near the stagnation line of the body. These two fronts separate from each other as one moves away from the stagnation line. The separation between the two fronts occurs as soon as the velocity component normal to the bow shock is equal to the detonation velocity. The separation between the bow shock and the reaction front is called the induction zone. Lehr's [4] experimental ballistic range shadowgraphs for Mach 5.11 and Mach 6.46 are shown in Figs. 1 and 2, respectively. In both cases, a tree-stream temperature of $292 \mathrm{~K}$ and a pressure of $42663.2 \mathrm{~N} / \mathrm{m}^{2}(320$ $\mathrm{mm}$ of $\mathrm{Ig}$ ) is used along with a stoichiometric mixture of hydrogen-air. Fig. 1 shows that the reaction from is separated from the bow shock near the stagnation line, and the instabilities or pulsations in the reaction front are visible tor Mach 5.11. Figure 2 is for Mach 6.46 case, and it is seen that the reaction front is coupled with the shock near the stagnation line. A close examination of the shadowgraphs reveals that as the flow crosses the bow shock the color changes from light to dark, indicating an increase in density. But, as the flow crosses the reaction front, the color changes from dark to light, indicating a decrease in density across the reaction tront. This is due to a large release of energy across the reaction front, causing an increase in the lemperature; since the pressure remains relatively constant, the density must decrease.

Behran el al. [5] conducled similar ballistic range experiments by tiring plastic spheres into hydrogen-air mixtures. Similar behavior of transition from stability to instability of the detonation waves was observed when the projectile velocities were decreased to nearly Chapman-Jouget velocity of the mixture.

Mivey and Toong [6] also conducted similar experiments where projectiles were tired into lean acetylene-oxygen and stoichiometric hydrogen-air mixtures. They proposed the wave interaction model to explain the instabilities in the structure of the detonation wave. Their model explains how compression waves can be formed when a new reaction front develops in the induction zone between the normal segment of the bow shock and the original reaction front. These 
compression waves lead to a cyclic process which is compatible with most of the ohserved features of the flow. However, the strength of the compression waves remained unresolved in their wave-interaction model, which is an important factor in determining if stich a model is physically possible. Alpert and loong [7] included the effect of the strength of the compression waves and proposed a modified form of the waveinteraction model.

Several researchers $[8-11]$ have recently altempled 10 numerically simulate Lehr's ballistic range experiments [4], hut have met with limited success. Youngster et al. [8] and lee et al. [9] simulated Lehr's experimental data for Mach 4.18, 5.11, and 6.46. They used Euler equations coupled with species equations to capture the shock and the reaction front. The reaction model used was hydrogen-air mixture of six specics and an inert gas such as $\Lambda$ rgon or Nitrogen and eight reactions. The flow field was found to he steady in conIrast to the experimental evidence that the flow field is, indeed, unsteady. For the test conditions of stoichiometric hydrogen-air mixture, the detomation wave speed of the mixture is Mach 5.11. Tixperimentally, it has heen demonstrated in Iehr's work that Mach 5.11 and 4.18 show structural instabilities of the detonation wave which disappear if the flight Mach number is increased heyond Mach 5.11. Further, the flow field was not well resolved. They used $32 \times 32$ and $57 \times 41$ size grids, respectively, in their blunt hody calculations. These grids were not sufficient to resolve the flow field correctly.

Wilson et al. [10] conducted a detailed numerical investigation of the shock-induced combustion phenomena. They used Euler equations and a 13-species and 33-reactions chemistry model. They showed the validity of the reaction models and the importance of grid resolution needed to properly model the flow physics. They did highly resolved calculations for l.ehr's Mach 5.11 and Mach 6.46 cases with adaptive grid. The calculations were not time accurate, so that the unstcady hehavior was not caplured.

Sussman et al. [11] also studied the instabilities in the reaction front for a Mach number of 4.79 . They also used luter cquations and a 1.3-species and 3.3-reactions chemistry model. They have proposed a new formulation? based on Iogarithmic transformation. It grently reduces the number of grid points needed to properly resolve the reaction front. They successfully simulated the unsteady case. Ilowever, the frequency was slightly underpredicted.

Matsto and Fujiwara [12] have studied the instabilitics of shock-induced combustion around an axisymmetric blunt body. They used Fuler equations and a simplified two-step chemistry model. They investigated the growth of periodic instabilities by a scries of simulations with various tip radii and showed that these periodic instabilities are related to shock-standoff distance and induction length. They proposed a new model based on McVey and Toong's model [6]. The instabilities in the reaction front were explained hy their model.

The instability in the structure of the reaction front originates in the induction zone which separates the bow shock and the exothermic reaction front in the nose region of the flow field and then spreads outwards. In order to capture the physical instabilities, the calculations must be carried out for long times to ensure that all relevant time scales are being captured. Since all numerical schemes have some numerical diffusion, which is dependent on the grid resolution, a coarse grid may damp these oscillations. Further, the numerical damping added to the scheme in the vicinity of the reaction front may damp or alter the instability modes. The objective of this study is to investigate, in detail, the shock-induced combustion phenomena for the premixed stoichiometric $\mathrm{H}_{2}$-air mixture flow at hypersonic speed (Mach 5.11), which is also the ChapmanJouget speed of the mixturc, past a $15 \mathrm{~mm}$ spherical projectile, including the stability of detonation waves. The analysis is carricd out using the axisymmetric version of the SPARK2I code [13], which incorporates a seven-species, seven-reactions combustion model for hydrogen-air mixture.

\section{BASIC GOVERNING EQUATIONS}

The physical model for analyzing the flow field is described by the Navier-Stokes and species contintuity equations. For two-dimensional axisymmetric flows, these equations are expressed in physical coordinates as

$$
\frac{\partial U}{\partial t}+\frac{\partial F}{\partial x}+\frac{\partial G}{\partial y}=H
$$

where vectors $\mathrm{U}, \mathrm{F}, \mathrm{G}$ and $\mathrm{H}$ are written as

$$
\begin{gathered}
U=\left[\begin{array}{c}
\rho \\
\rho u \\
\rho v \\
\rho E \\
\rho f_{i} \\
\cdot \\
\cdot
\end{array}\right] \\
F=\left[\begin{array}{c}
\rho u \\
\rho u^{2}-\sigma_{x} \\
\rho u v-\tau_{x y} \\
\left(\rho E-\sigma_{x}\right) u-\tau_{x y} v+q_{x} \\
\rho f_{i}\left(u+\tilde{u}_{i}\right) \\
\cdot \\
\cdot
\end{array}\right]
\end{gathered}
$$




$$
\begin{aligned}
& G=\left[\begin{array}{c}
\rho v \\
\rho u v-\tau_{x y} \\
\rho v^{2}-\sigma_{y} \\
\left(\rho E-\sigma_{y}\right) v-\tau_{x y} u+q_{y} \\
\rho f_{i}\left(v+v_{i}\right) \\
\cdot
\end{array}\right] \\
& H=\frac{1}{y}\left[\begin{array}{c}
\rho v \\
\left(\rho v u+\tau_{x y}\right) \\
\rho v^{2}+\tau_{y y}-\tau_{\theta \theta} \\
\left(\rho E+\tau_{y y}\right) v+\tau_{x y} u+q_{y} \\
\omega_{i} \\
\cdot \\
\cdot
\end{array}\right]
\end{aligned}
$$

The other terms appearing in vectors F, G, and II are defined as

$$
\begin{aligned}
& \sigma_{x}=-p+2 \mu \frac{\partial u}{\partial x}+\lambda \nabla \cdot u \\
& \sigma_{y}=-p+2 \mu \frac{\partial v}{\partial y}+\lambda \nabla . u \\
& \tau_{x y}=\mu\left[\frac{\partial u}{\partial y}+\frac{\partial v}{\partial x}\right] \\
& \tau_{y y}=-\frac{2}{3} \mu\left(2 \frac{\partial v}{\partial y}-\frac{v}{y}-\frac{\partial v}{\partial x}\right) \\
& \tau_{t \theta}=-\frac{2}{3} \mu\left(2 \frac{v}{y}-\frac{\partial v}{\partial y}-\frac{\partial u}{\partial x}\right) \\
& q_{x}=-k \frac{\partial T}{\partial x}+\rho \sum_{i=1}^{N_{1}} h_{i} f_{i} \tilde{u}_{i} \\
& \varphi_{y}=-k \frac{\partial T}{\partial y}+\rho \sum_{i=1}^{N_{+}} h_{i} f_{i} \bar{v}_{i} \\
& p=\rho R_{1} T \sum_{i=1}^{N_{i}} \frac{f_{i}}{M_{i}} \\
& h_{i}=h_{i}^{R}+\int_{T^{H}}^{T} C_{p_{i}} d T \\
& \frac{C_{p_{1}}}{R_{i}}=A_{i}+B_{i} T+C_{i} T^{2}+D_{i} T^{3}+E_{i} T^{4}
\end{aligned}
$$

In Iiq. (1) only ( $\left.\mathrm{N}_{\mathrm{s}}-1\right)$ species equations need to be considered in the formulation since the mass fraction of the species is prescribed by satisfying the constraint equation

$$
\sum_{i=1}^{N_{1}} f_{i}=1
$$

The specific heat at constant pressure for each species is prescribed in Eq. (11) by a fourth-order polynomial in temperature. The multicomponent diffusion equation for the diffusion velocity of the $\mathrm{i}^{\text {th }}$ species

$$
\tilde{u}_{i}=\tilde{u}_{i} i+\tilde{u}_{j} j
$$

is as follows :

$$
\begin{gathered}
\nabla X_{i}=\sum_{j=1}^{N_{s}}\left(\frac{X_{i} X_{j}}{D_{i j}}\right)\left(u_{j}-\tilde{u}_{i}\right)+ \\
\left(\frac{\rho}{p}\right) \sum_{j=1}^{N_{s}} f_{i} f_{j}+\left(f_{i}-X_{i}\right)\left(\frac{\nabla p}{p}\right)+ \\
\sum_{j=1}^{N_{6}}\left(\frac{X_{i} X_{j}}{\rho D_{i j}}\right)\left(\frac{D_{T, j}}{f_{j}}-\frac{D_{T, i}}{f_{i}}\right)\left(\frac{\nabla T}{T}\right)
\end{gathered}
$$

It may be noted that this equation has to be applied only to $\left(\mathbf{N}_{\mathrm{s}}-1\right)$ species. The diftusion velocity for the remaining species is prescribed by satisfying the constraint equation $\sum_{i=1}^{N_{i}} f_{i} \bar{u}_{i}=0$, which ensures the consistency. In Lq.(7), it is convenient to assume that the body force vector per unit mass is negligible. In addition, thermal diffusion is considered to be negligible when compared with the binary dillusion coetficient.

\section{CHEMISTRY AND THERMODYNAMIC MODELS}

Chemical reaction rate expressions are usually determined by summing the contributions from each relevant reaction path to obtain the total rate of change of each species. Each path is governed by a law of mass action expression in which the rate constants can be determined from a temperature dependent Arrhenius expression. In vector $\mathrm{II}$, the tern $\omega_{i}=M_{i} C_{i}^{\prime}$ represents the net rate of production of species $i$ in all chemical reactions and is modelled as follows :

$$
\begin{aligned}
& \sum_{i=1}^{N_{i}} \dot{\nu_{j i} S_{i}}=\sum_{i=1}^{N_{i}} \nu_{j i}^{\prime \prime} S_{i} ; j=1, \ldots N_{r}
\end{aligned}
$$

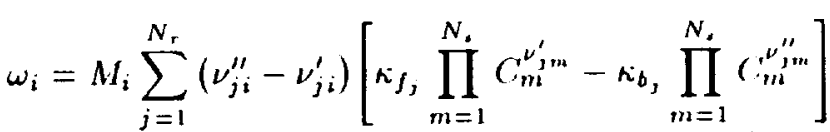

where Eq.(14) is a representation of an $\mathrm{N}_{\mathrm{r}}$-step chemical reaction, and Eq.(15) is the production rate for the $\mathrm{i}^{\text {th }}$ species as determined from the law of mass action. 
The reaction constants $\kappa_{\mathrm{fj}}$ and $\kappa_{\mathrm{bj}}$ are calculated from the following equations

$$
\begin{gathered}
\kappa_{j j}=\Lambda_{j} T^{\alpha j} \exp \left(\frac{-\epsilon_{j}}{R_{u} T}\right) ; j=1, \ldots N_{r} \\
\kappa_{b j}=\frac{\kappa_{j_{j}}}{\kappa_{e q_{j}}} ; j=1, \ldots N_{r}
\end{gathered}
$$

The equilibrium constant appearing in IQ.(18) is given by

$$
\kappa_{\text {eq, }}=\left(\frac{1}{R_{n} T}\right)^{\Delta n,} \exp \left(\frac{-\Delta C_{f_{1}}}{R_{11} T}\right) ; j=1, \ldots N_{r}
$$

where

$$
\begin{gathered}
\Delta n_{j}=\sum_{i=1}^{N_{s}} \nu_{j i}^{\prime \prime}-\sum_{i=1}^{N_{1}} \nu_{j i}^{\prime} ; j=1, \ldots N_{r} \\
\Delta G_{R}=\sum_{i=1}^{N_{s}} \nu_{j i}^{\prime \prime} g_{i}-\sum_{i=1}^{N_{s}} \nu_{j i}^{\prime} g_{i} ; j=1, \ldots N_{r} \\
\frac{g_{i}}{R_{i}}=A_{i} T(1-\ln T)-\left(\frac{B_{i}}{2}\right) T^{2}-\left(\frac{C_{i}}{6}\right) T^{3} \\
-\left(\frac{D_{i}}{! 2}\right) T^{4}-\left(\frac{E_{i}}{20}\right) T^{5}+F_{i}-\left(i_{i} T ; i=1, \ldots . N_{s}\right.
\end{gathered}
$$

The forward rate for each reaction is determined from Iq.(17) which is based on the Arrhenius law. The appropriate constants $\Lambda_{j}, \alpha_{j}$, and $\epsilon_{j}$ for the $1 I_{2}$-air reaction system can be found in [14]. The reverse rate is then calculated from Fq. (18). It should he noted that the Gibb's free energy of each species in $g_{i}$ is obtained from the expression for $\mathrm{C}_{\mathrm{pi}}$.

The hydrogen-air combustion mechanism used in this work is hased on the Jachimowski Hydrogen-air model [14] which uses seven species and seven reactions. The species are $\mathrm{N}_{2}, \mathrm{O}_{2}, \mathrm{H}_{2}, \mathrm{OHI}, \mathrm{H}_{2} \mathrm{O}, \mathrm{O}$, and $\mathrm{II}$. Each of the seven reactions can proceed in the forward and hackward directions. The reactions are
1) $\mathrm{O}_{2}+\mathrm{H}_{2} \rightleftharpoons \mathrm{OH}+\mathrm{OHI}$
2) $\mathrm{O}_{2}+\mathrm{II}=\mathrm{OII}+\mathrm{O}$
3) $\mathrm{H}_{2}+\mathrm{OHI}=\mathrm{H}_{2} \mathrm{O}+\mathrm{H}$
4) $\mathrm{H}_{2}+\mathrm{O}=\mathrm{OHI}+\mathrm{HI}$
5) $\mathrm{OHI}+\mathrm{OII} \rightleftharpoons \mathrm{II}_{2} \mathrm{O}+\mathrm{O}$
6) $\mathrm{OH}+\mathrm{H}+\mathrm{N}_{2} \rightleftharpoons \mathrm{I}_{2} \mathrm{O}+\mathrm{N}_{2}$
7) $\mathrm{H}+\mathrm{H}+\mathrm{N}_{2} \rightleftharpoons \mathrm{H}_{2}+\mathrm{N}_{2}$

\section{METHOD OF SOLUTION}

The governing equations are transformed from the physical domain $(\mathrm{x}, \mathrm{y})$ to a computational domain $(\xi$, $\eta$ using an algebraic grid generation technique. In the computational domain, Eq. (1) is expressed as

$$
\frac{\partial U}{\partial t}+\frac{\partial \hat{F}}{\partial \xi}+\frac{\partial \hat{G}}{\partial \eta}=\hat{H}
$$

where

$$
\begin{gathered}
\hat{U}=U J, \hat{F}=F y_{\eta}-G x_{\eta} \\
\hat{G}=G x_{\xi}-F y_{\xi}, \hat{H}=H . J \\
J=x_{\xi} y_{\eta}-y_{\xi} x_{\eta}
\end{gathered}
$$

The governing equations are solved using MacCormack's [17] method. The scheme is second-order accurate in time and space. This results in a spatially and temporally discrete, simultaneous system of equations at each grid point. The system of equations is solved subject to initial and boundary conditions. At the supersonic inlow houndary, all flow quantities are specified as free-stream conditions. Al the supersonic outflow boundary, all now quantities are extrapolated from interior grid points. Although full N-S equations are used, the slip conditions are used to mumerically simulate the inviscid flow. A flow tangency or slip boundary condition is implied on solid wall. The wall temperature and pressure are extrapolated from interior grid points. Initial conditions are obtained by specifying free-stream conditions throughout the flow field. The resulting set of equations is marched in time.

The I ax-Wendroff type schemes are inherently unstable and, hence, higher-order numerical dissipation terms are oflen necessary to get a stable solution. For a non-reacting flow field, an artificial viscosity based on temperature and for pressure is traditionally used, but in chemically reacting flows, in addition to temperature and pressure gradients, one can also have very strong species concentration gradients. To suppress the numerical oscillations in the induction zone where the gradients in the concentration of reactants and products are very strong, additional artificial viscosity based on $\mathrm{H}_{2} \mathrm{O}$ mass fraction is used similar to the one used by Singh et al. [15].

\section{RESULTS AND DISCUSSIONS}

The stoichiometric chemical reaction for a hydrogen-air system can be written as

$$
2 \mathrm{H}_{2}+\mathrm{O}_{2}+3.76 \mathrm{~N}_{2} \rightarrow 2 \mathrm{H}_{2} \mathrm{O}+3.76 \mathrm{~N}_{2}
$$

When a blunt body is moving through a reactive mixture at hypersonic speeds, a bow shock is formed ahead of the body, and the temperature of the fuel-air mixture after the bow shock is sufficiently high to initiate the reaction. Once the ignition starts, chemical energy is released and another discontinuity known as reaction front is formed. In the induction zone, the temperature and the pressure remain relatively constant at the post shock conditions, whilc the concentrations of radicals build up very rapidly. 
Because of the symmetry, only one half of the flow field is calculated. Figure 3 shows the typical grid which contains $101 \times 78$ grid points (101 normal to the body and 78 along the body). For clarity, every fourth grid point is shown in the figure. For the present case of a stoichiometric hydrogen-air mixture, the Chapman-Jouget velocity is the same as the velocity of the projectile for the Mach 5.11 case. Ilowever, for the Mach 6.46 case, the projectile speed is significantly above the detonation velocity of the mixture. Unsteady flow phenomenon can occur if the free-stream velocity of the projectile is around the C-J detonation velocity of the mixture. For both cases, the residuals were dropped by three orders in 12,000 iterations and then remained constant. Figure 4 shows the contour plot of density for the Mach 5.11 case. The bow shock and the reaction front can be seen clearly in the figure. They are separated from each other by the induction distance. The separation (i.e., the induction distance) is minimum near the stagnation line and increased away from it. This is because near the stagnation line, bow shock is almost normal and, hence, the post shock temperature is maximum; thus, induction distance is minimum. Away from the stagnation line, the shock strength decreases, thereby decreasing the post-shock temperature and, hence, increasing the induction distance. A comparison with Iig. 1 shows that all the flow features are very well captured. ligure 5 shows the corresponding plot which has been enlarged for clarity. The bow shock is very crisp and smooth, whereas the reaction front is wrinkled. The pulsations or instabilities which arise at the stagnation point move all through the reaction front. The maximum density is seen to be just after the bow shock, and minimum density is after the reaction front. The shock standoff distance is comparable to the Lehr's shadograph. Figure 6 shows the contour plot for temperature, and Fig. 7 shows the corresponding enlarged view. Again, it is seen that the bow shock is very smooth, but the reaction fromt which separates from the bow shock near the stagnation line shows pulsations. As explained earlier, the post-shock temperature is maximum near the stagnation line and gradually decreases away from it. Also, due to the exothermic nature of the reaction, the temperature further increases as the reation proceeds. The peak temperature occurs at the stagnation point. Figure 8 shows the temperature along various $j=$ constant grid lines. The post shock stagnation point temperature is $3150^{\circ} \mathrm{K}$, which compares very well with Ref. [10]. As the gas encounters the bow shock, the temperature increases abruptly. Immediately after the shock, the temperature stays constant for a short distance and then begins to increase due to exothermic reactions. The induction zone decreases with increasing temperature, as chenical energy release will be faster for higher temperatures. Also, one can see the unsteadiness in the reaction front. This unsteadiness originates from the induction zone near the stagnation line and then travels downstream. The contour plots for water mass traction are shown in Figs. 9 and 10. At the end of the combustion zone, the temperature is high enough to start the combustion. As the reaction proceeds, the water mass fraction increases rapidly. The oscillations similar 10 temperature and densily profiles can be seen here. The instability is characterized by an almost regular periodic wave motion having a constant irequency. Similar instability has been observed experimentally in L.chr's work. Figure 11 shows the pressure contour. Again, the bow shock is clearly visible in the tigure, and the pressure jump across the shock is comparable with Ret [9]. Figure 12 shows the line plot for pressure along various $\mathrm{j}=\mathrm{conns}$ ant grid lines. As the flow crosses the shock, it encounters the pressure jump. The pressure decreases slightly after the shock. The Von Nemmann spike, which is characteristic of reacting llows, is also visible. The post sheck oscillation in pressure along the stagnation line has also been observes in Ret. [9]

The instability in the reaction front has been explained by the wave interaction model as proposed by McVey and Toong [6] and as modilied by Matsuo and I ujiwara [11]. Figure 13 shows the wave interaction model in terms of the $x-t$ diagram on the stagnation streamline between the bow shock and the reaction tront. The diagram shows the $x-t$ plot for waler mass iraction with an overlay of pressure. liirst, the contact discontinuty approaches the original reaction iromt. The hot gases behind the contact discontinuity begin to react, generating compression or pressure waves which propagate upstream and downstream. The compression wave which propagates upstream interacts wiih the bow shock and produces a contact discontinuity behind the bow shock. The hot gases on the contact discontinuty behind the bow shock begin to react, and thus, generating another set of compression waves. At a somewhat later time, the contact discontinuity reaches the position of the original reaction front, extinguishing the reaction at this point because no more unreacted gas exists there, and the rate of energy release is effectively reduced, and thus, generating rarefiation waves. The reaction front begins to recede becaluse of increasing induction time of the colder fluid. The compression wave travelling towards the blunt body gets rellected from the body and travels back to the reaction tront and causes a change in the ignition location, and a new pressure wave is created and then the cycle is repeated.

Figure 14 shows the $x-t$ plot for density along the stagnation line. The shock fromt is smooth, but the periodic oscillations of the reaction front are clearly visible. These periodic oscillations are much more clear from liig. 15, which is the $x-t$ plot for water mass iraction along the stagnation line. If one sees these oscillations very clesely, it will be clear that the water mass production rate, which is also a measure of energy release, continues to increase, and then decreases cventually to 
zero water mass production and, hence, zero energy release. This is the point of extinguishment of the reaction front. The reaction almost comes to a standstill at this point. Since the new reaction front generated has high energy release (and, hence, high water mass production rate), it sends new sets of compression waves, which propagate hoth upstream and downstream, and the above cycle is repeated. Figure 16 shows the $x-t$ plot for temperature along the stagnation line. The periodic oscillations of the reaction front similar to water mass fraction is noticed.

To further investigate the unsteady nature of the How ficld, a Fouricr analysis of the flow field was conducted. For this, data at various sample stations along the $j=61$ grid line were stored for 30,000 iterations to get good temporal resolutions. The grid used was $101 \times 78$, and all calculations were time accurate. Figure 17 shows the amplitude vs frequency plot obtained hy using Fourier transform. The flow field spectrum is well resolved, and it clearly shows the fundamental frequency of $1.2 \mathrm{e}+6 \mathrm{Iz}$ and a peak amplitude of 0.004. It also shows subharmonics and high-frequency numerical noise. Experimental fundamental frequency, as given in Ref. [16], is $1.96 \mathrm{e}+6$ 117. The discrepancies hetween the experimental and the numerical valuc could be due to improper grid resolution. The calculations were then repeated for a finer grid $(131 \times 101)$. The grid asnect ratio was kept the same in hoth the cases. Figure 18 shows the frequency spectrum for the flow ficld with the fincr grid. The sample stations have the same physical locations as in the previous case. The dominant frequency now is $2.0 \mathrm{e}+6 \mathrm{Iz}$, and the amplitude is 0.004 . This frequency is in close agreement with the experimental value of $1.96 e+6$ II7. The above calculations were repeated once again for another finer grid of $197 \times 152$. The grid aspect ratio was kept the same and the sample stations have the same physical locations as in the previous cases. Figure 19 shows the frequency spectrum for this grid. The dominant frequency now is $2.1 \mathrm{e}+6 \mathrm{~Hz}$, and the amplitude is 0.004 . Thus, refining the grid has not changed the frequency and therefore, the oscillations in the reaction front are physical.

The results for the Mach 6.46 case will now be presented. As mentioned earlier, this is a superdetomative case, i.e., projectile velocity is higher than the detonation velocity of the mixture.

The temperature contours are shown in Fig. 20. Qualitatively the results are similar to the previous case except near the stagnation zone; the bow shock and the reaction front are now almost coupled due to very small induction distance (hecause of higher post-shock temperature). The two fronts scparate from each other slightly downstream.

Figure 21 shows the water mass-fraction contours. Ilere, in contrast to the previous case, the reaction front is very smooth. The periodic instabilities, which were clearly visible previously, cannot be seen. This is in agreement with the experimental result (see Fig. 2). The frequency spectrum and the stability for Mach 6.46 has not been analyzed in the present study but will be carried on in future work.

\section{CONCLUSIONS}

A numerical study is carried out to investigate the shock-induced combustion in premixed hydrogenair mixture. The calculations have been carried out for Mach 5.11 and 6.46. The Mach 5.11 case was found to he unsteady with periodic oscillations. The frequency of oscillations was calculated and was found to he in good agreement wilh the experimentally ohserved frequency. The Mach 6.46 case was found to be macroscopically stable, thus supporting the existing view that it is possible to stahilize the shock-induced combustion phenomena with sufficient level of overdrive.

\section{ACKNOWLEDGMENT}

The authors would like to thank Drs. Ajay Kumar and Mark Carpenter of N $A$ SA Langley Research Center for many helpful discussions during the course of this work.

\section{REFERENCES}

1. Cambier, J. L. and Adelman H., "Numerical Simulations of an Ohlique Detonation Wave Engine," AIAA l'aper 88-0063, January 1988.

2. White, M. E.., Drummond, J. P., and Kumar, $\Lambda$ jay, "Evolution and Status of CID Techniques for Scramjel Applications," AlAA Paper 86-0160, January 1986.

3. Alamanchuk, T. and Sislian J., "On-And-Off Design Performance Analysis of Ilypersonic Detonation Wave Ramjets," AIA $A$ Paper 90-2473, July 1990.

4. I.ehr, H. F., "lixperiments on Shock-Induced Combustion,"Acta Astronautica, Vol. 17, September 1972, pp. 589-586.

5. Behrens, II., Struth, W., and Wecken F., "Studies of Ilypervelocity Firings into Mixtures of Hydrogen with Air or with Oxygen," Tenth Symposium (International) on Combustion, 1965, pp. 245-252.

6. McVey, J. B. and Toong, T. Y., “Mechanism of Instabilities of Exothermic Hypersonic Blunt-Body Flows," Combustion Science and Technology, Vol. 3, 1971 , pp. 63-76.

7. Alpert, I.. R. and Toong, T. Y., "Periodicity in Exothermic Ilypersonic Flows about Blunt Projectiles," Acta Astronautica, Vol. 17, September 1972, pp. $539-560$.

8. Yungster, S., Fherhardt, S., and Bruckner, $\boldsymbol{A}$. P., "Numerical Simulation of Shock-Induced Combustion by Iligh-Speed Projectiles in Detonable Gas Mixlures," АI $\Lambda$ Paper 89-0673, July 1989. 
9. Lee, S. and Deiwert, G. S., " Calculation of Non-equilibrium Hydrogen-Air Reaction with Implicit Flux Vector Splitting Method," AIAA Paper 89-1700, 1989.

10. Wilson, G. J. and MacCormack R. W., "Modelling Supersonic Combustion Using a Fully-Implicit Numerical Method," AIAA Paper 90-2307, July 1990.

11. Sussman, A. M. and Wilson, G. J., "Computation of Chemically Reacting Flow using a Logarithmic form of the Species Conservation Equations," Proceedings of Fourth International Conference on Numerical Combustion, Tampa, Fl., December 2-4, 1991, pp. 224-227.

12. Matsuo, A. and Fujiwara T., "Numerical Simulations of Shock-Induced Combustion around an Axisymmetric Blunt Body," AIAA Paper 91-1414, June 1991.

13. Drummond, J. P., Rogers, R. C., and Hussaini,
M. Y., "A Detailed Numerical Model of a Supersmic Reacting Mixing Layer," AIAA Paper 86-1427, June 1986.

14. Jachimowski, C. J., “An Analytical Study of the Ilydrogen-Air Reaction Mechanism with Application to Scramjet Combustion," NASA TP-2791, 1988.

15. Singh, D. J., Carpenter, M. II., and Kumar, A., "Numerical Simulation of Shock-Induced Combustion/Detonation in a Premixed $\mathrm{H}_{2}$-Air Mixture Using Navier-Stokes Equations," AIAA Paper 9l-3358, Junc 1991.

16. Anonymous, Rapport-Bericht CO $7 / 73$, Institut Franco-Allenmand De Recherches De Saint-1.ouis, Kolloquium Uber Gasdetonationen, obgehalten in ISI. am 22.10.1973, ISI -Beitrage.

17. MacCormack, R. W., "The Effect of Viscosity in Hypervelucity Impact Cratering," AlAA Paper 69-354, April-May 1969. 


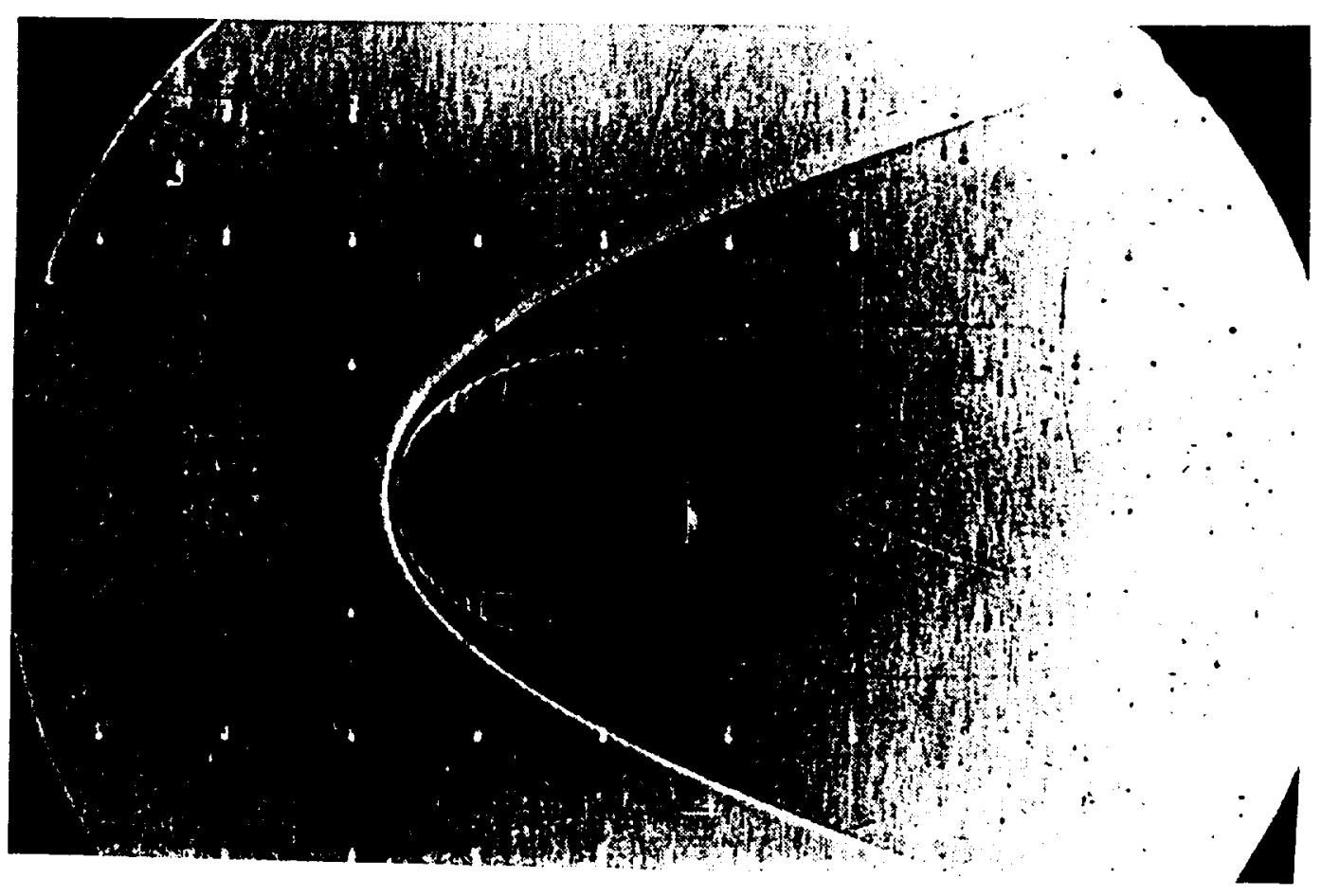

Figure I Shadowgraph of a spherical nose projectile moving at Mach 5.11 into a premixed stoichiometric hydrogen-air mixture.

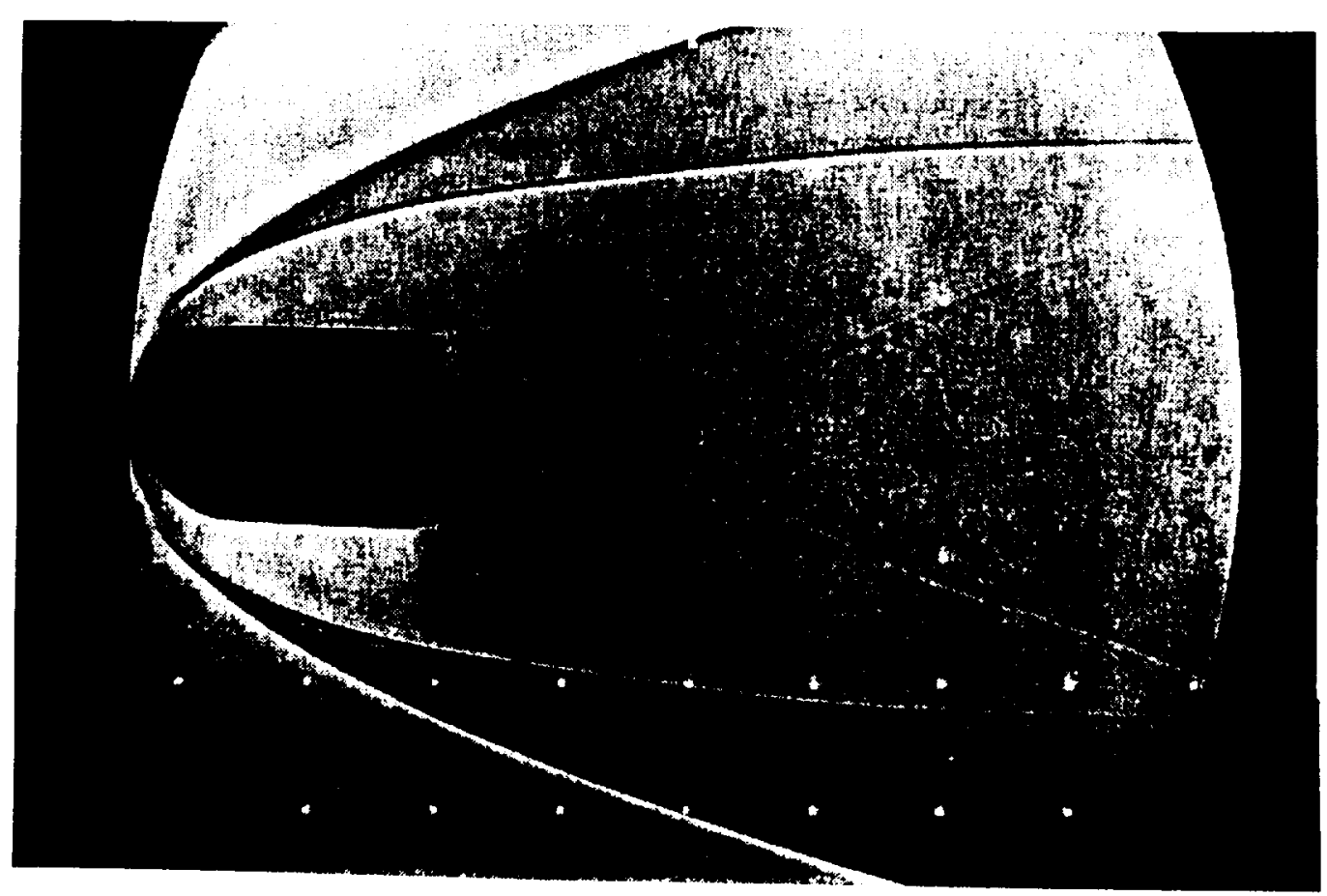

Figure 2 Shadowgraph of a spherical nose projectile moving at Mach 6.46 into a premixed stoichiometric hydrogen-air mixture. 


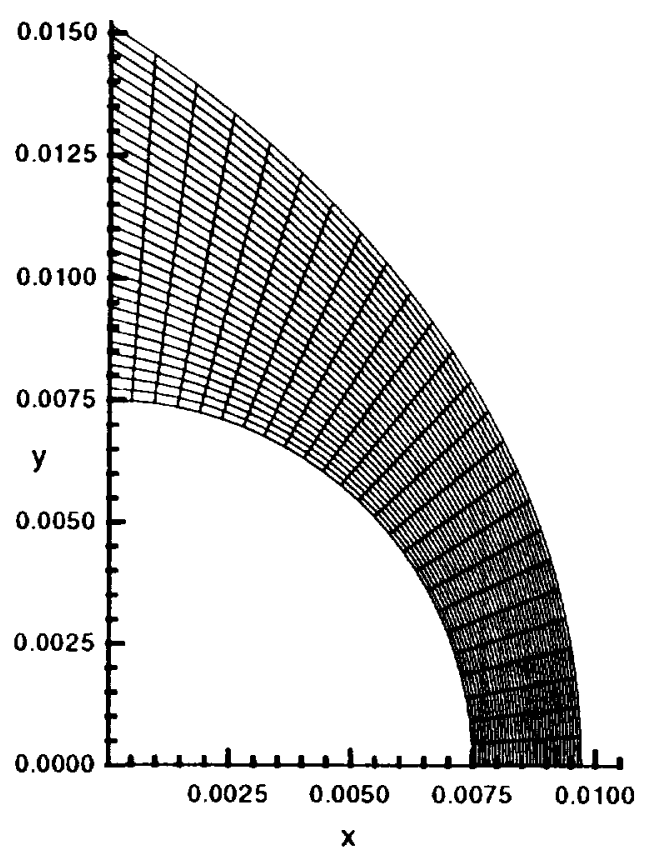

Figure 3 Typical grid for the calculation

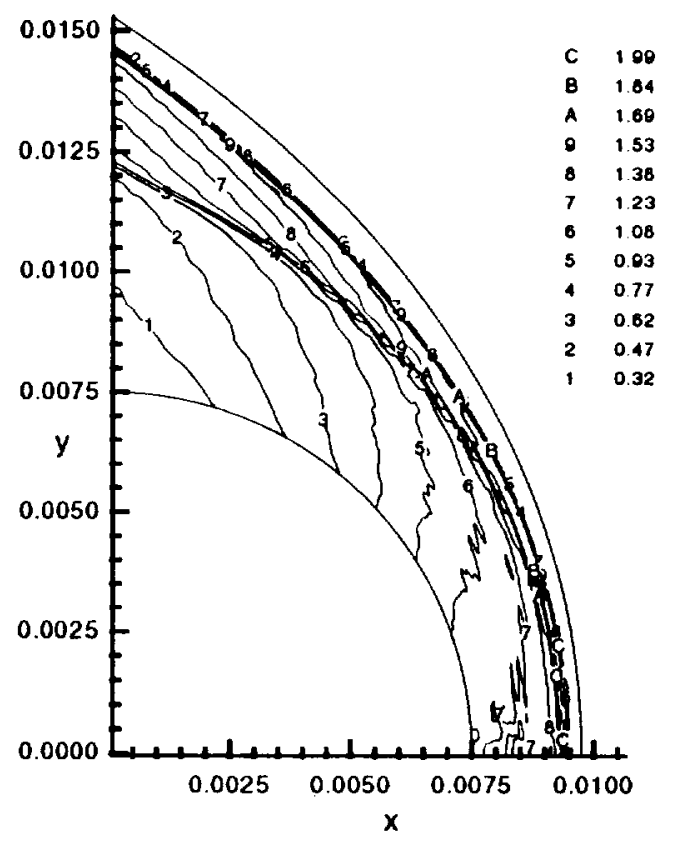

Figure 4 Density contours for Mach 5.11

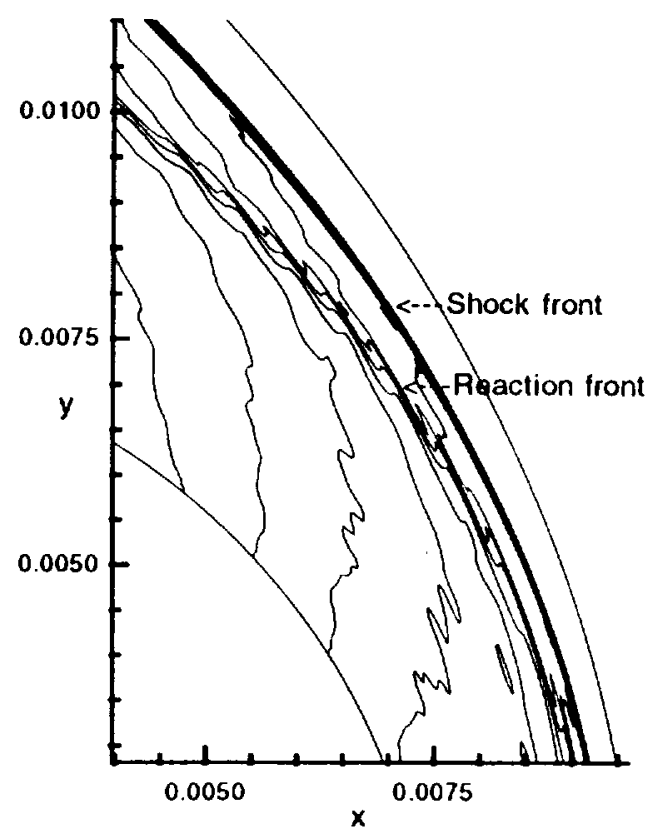

Figure 5 Enlarged view of density contours for Mach 5.11

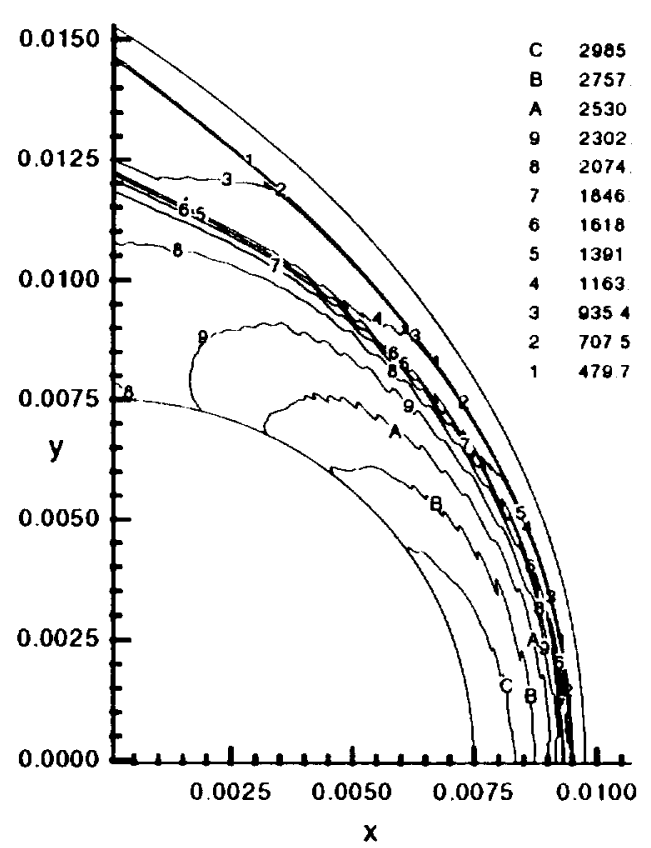

Figure 6 Temperature contours for Mach 5.11 


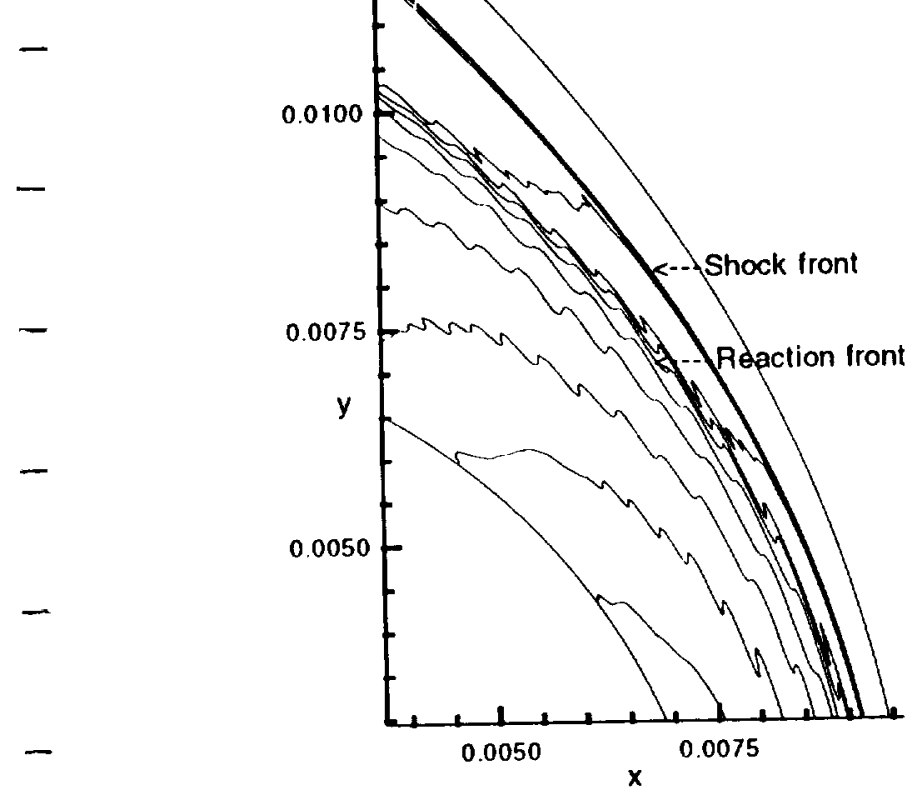

Figure 7 Enlarged view of temperature contour for Mach 5.11

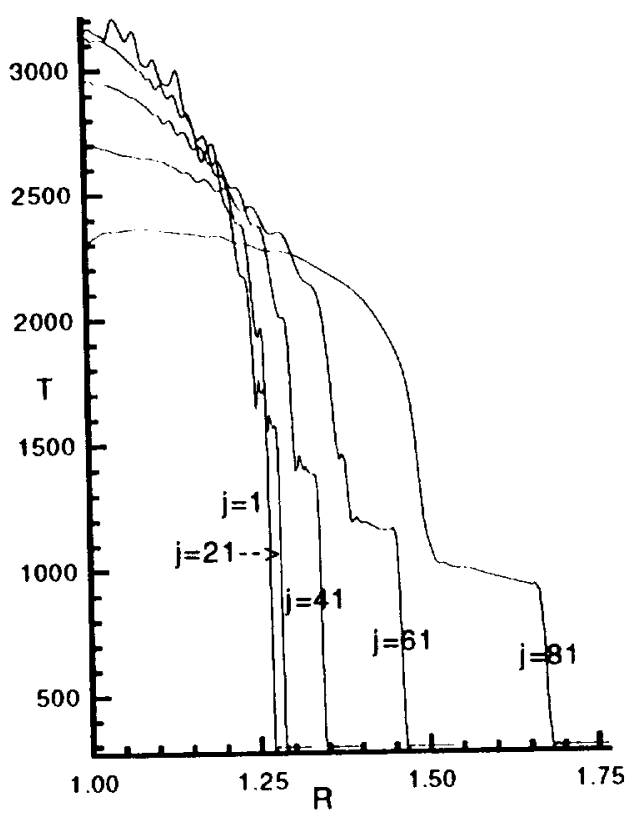

Figure 8 Temperature vs radius along various $j=$ constant grid lines

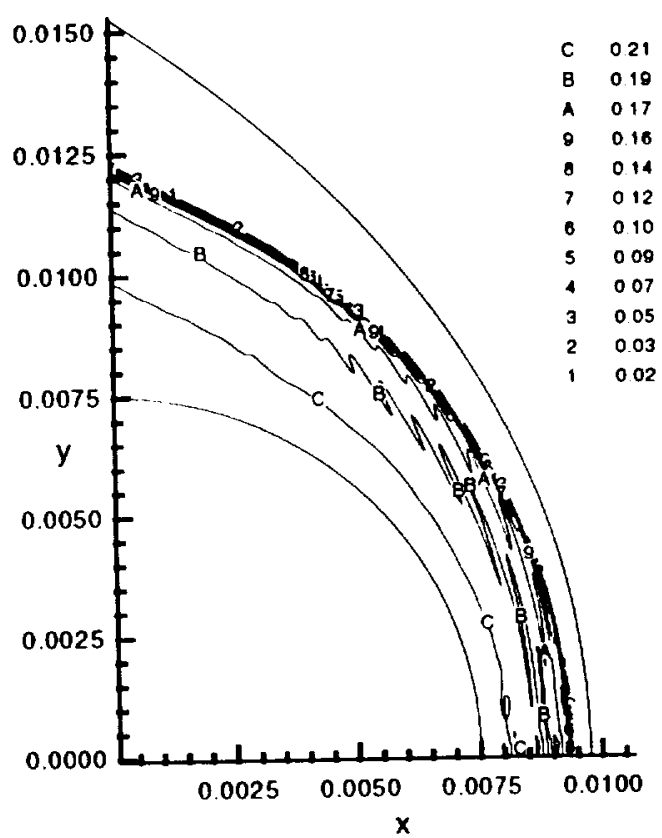

Figure 9 Water mass fraction contours for Mach 5.11

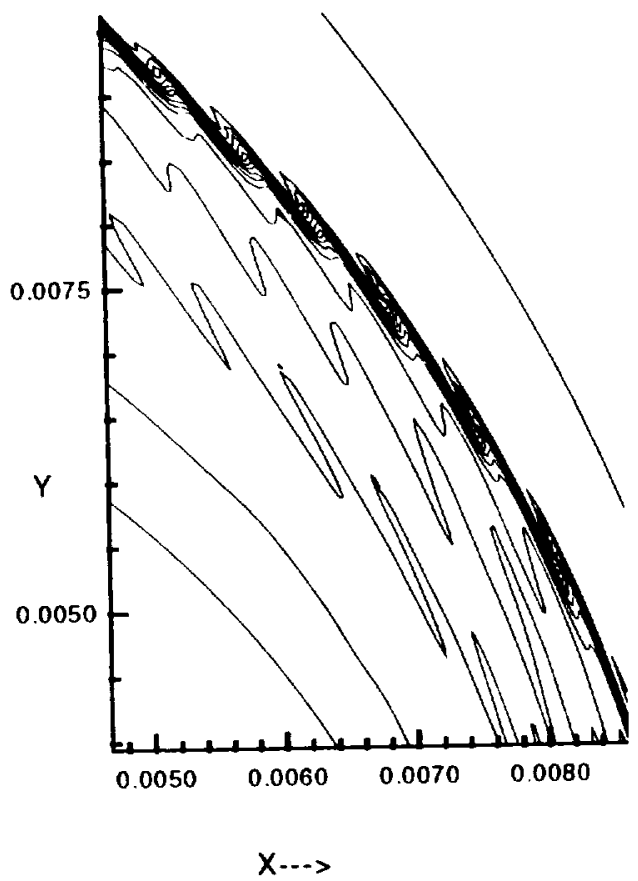

Figure 10 Enlarged view of $\mathrm{H}_{2} \mathrm{O}$ mass fraction contours 


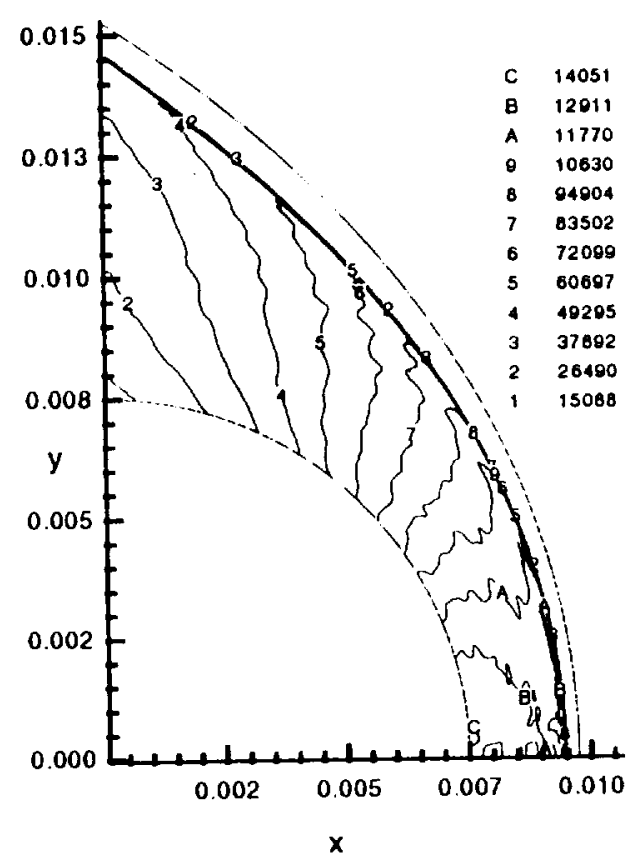

Figure 11 Pressure contours for Mach 5.11

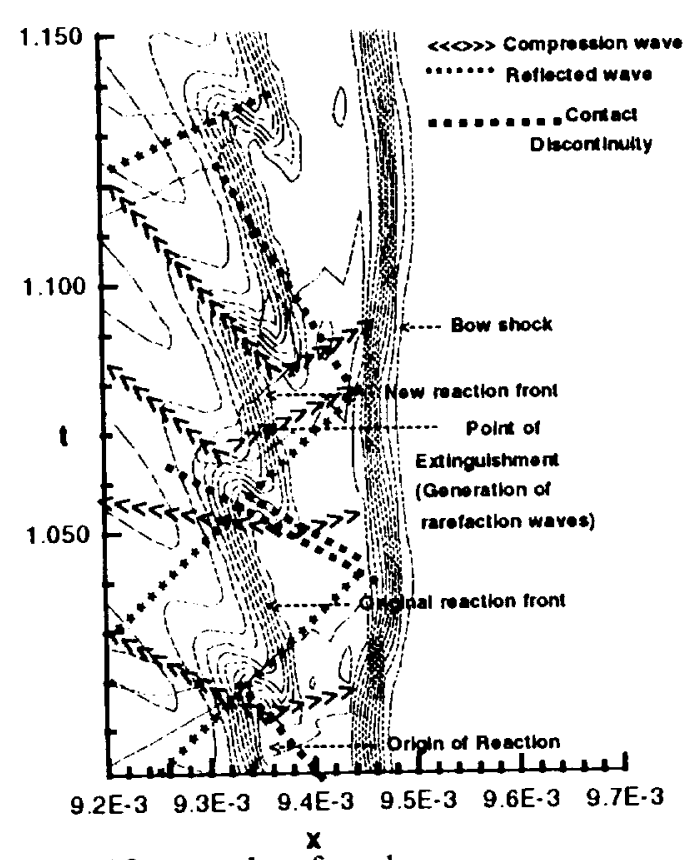

Figure $13 x-t$ plot for the wave interaction model $\left(\mathrm{H}_{2} \mathrm{O}\right.$ contours with an overlay of pressure)

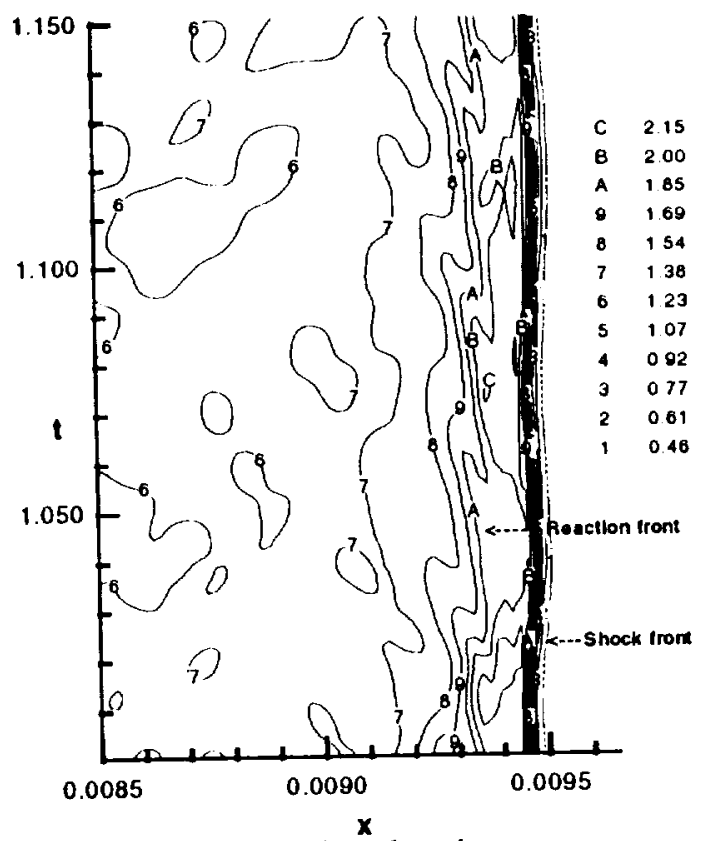

Figure $14 x-t$ plot for density along the stagnation line
Figure 12 Pressure vs radius along various $j=$ constant grid lines 


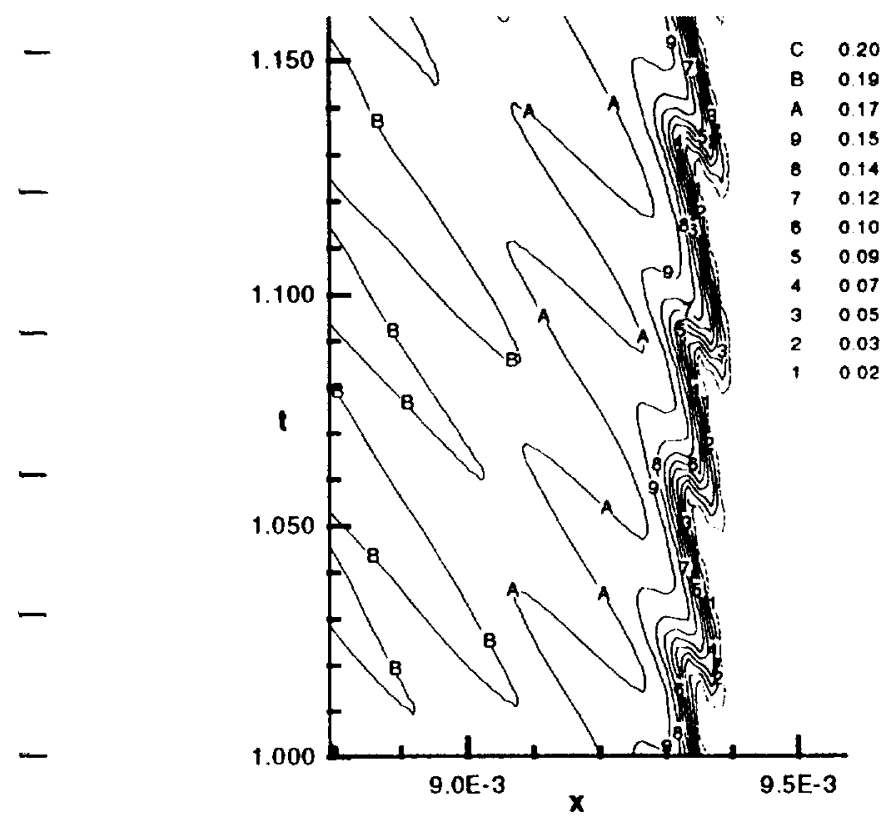

Figure $15 x$-t plot for $\mathrm{H}_{2} \mathrm{O}$ mass-fraction along stagnation line

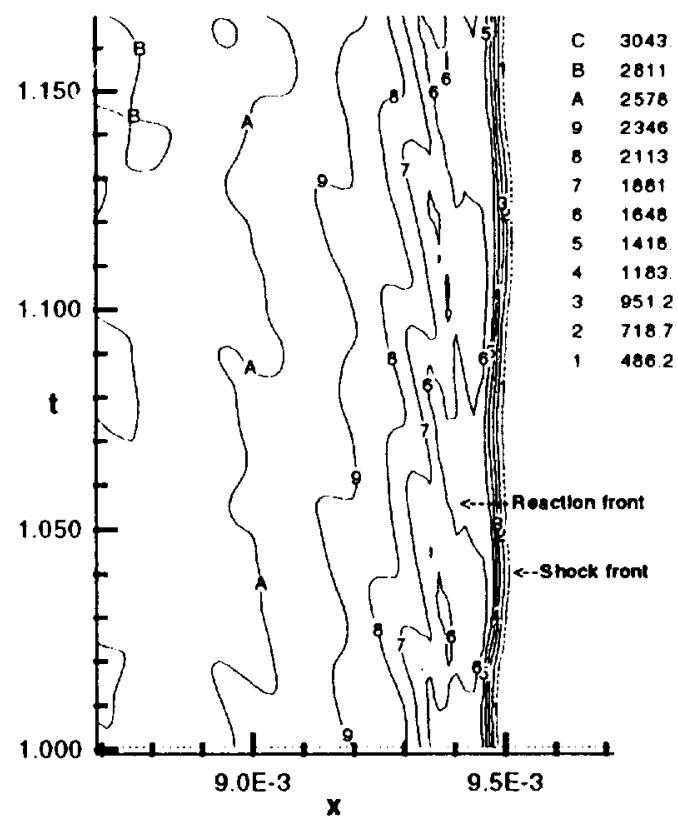

Figure $16 \mathrm{x}$-t plot for temperature along stagnation line

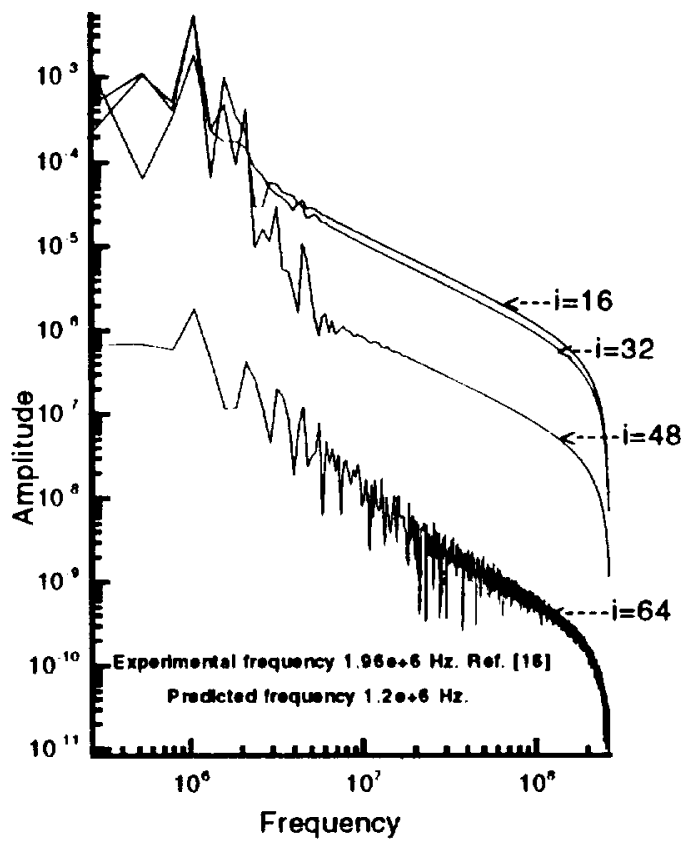

Figure 17 Temporal frequency spectrum of water mass fraction for $101 \times 78$ grid size.

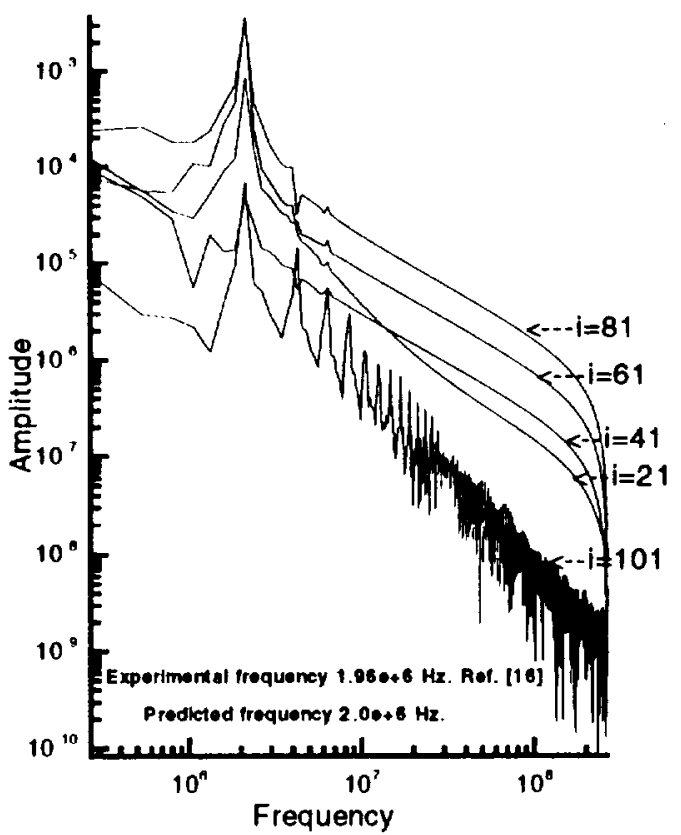

Figure 18 Temporal frequency spectrum of water mass fraclion for $131 \times 101$ grid size. 


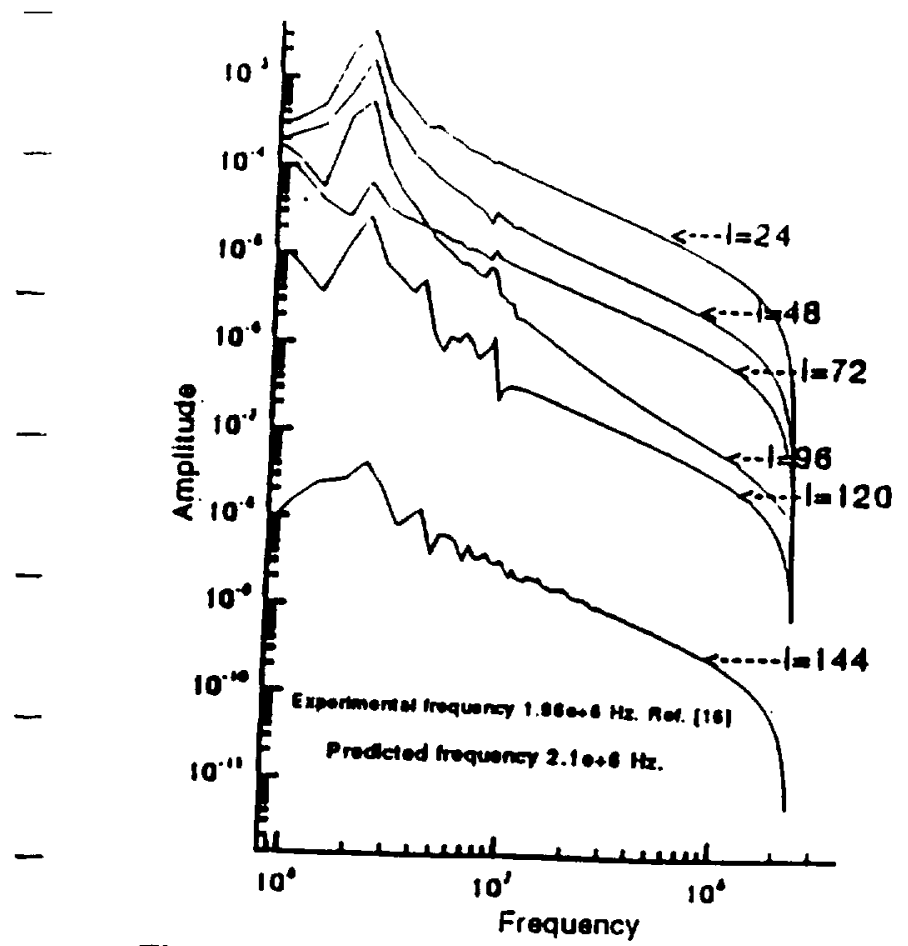

Figure 19 Temporal frequency spectrum of water mass fraction for $197 \times 152$ grid size.

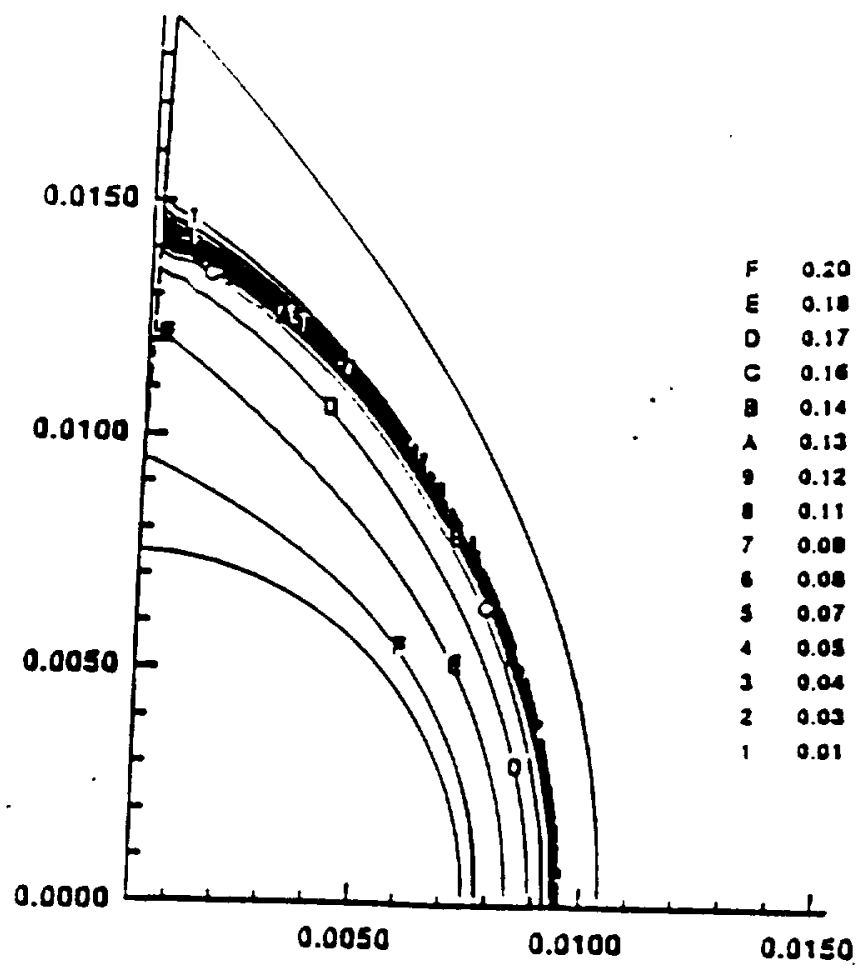

Figure 21 Water mass fraction contours for Mach 6.46

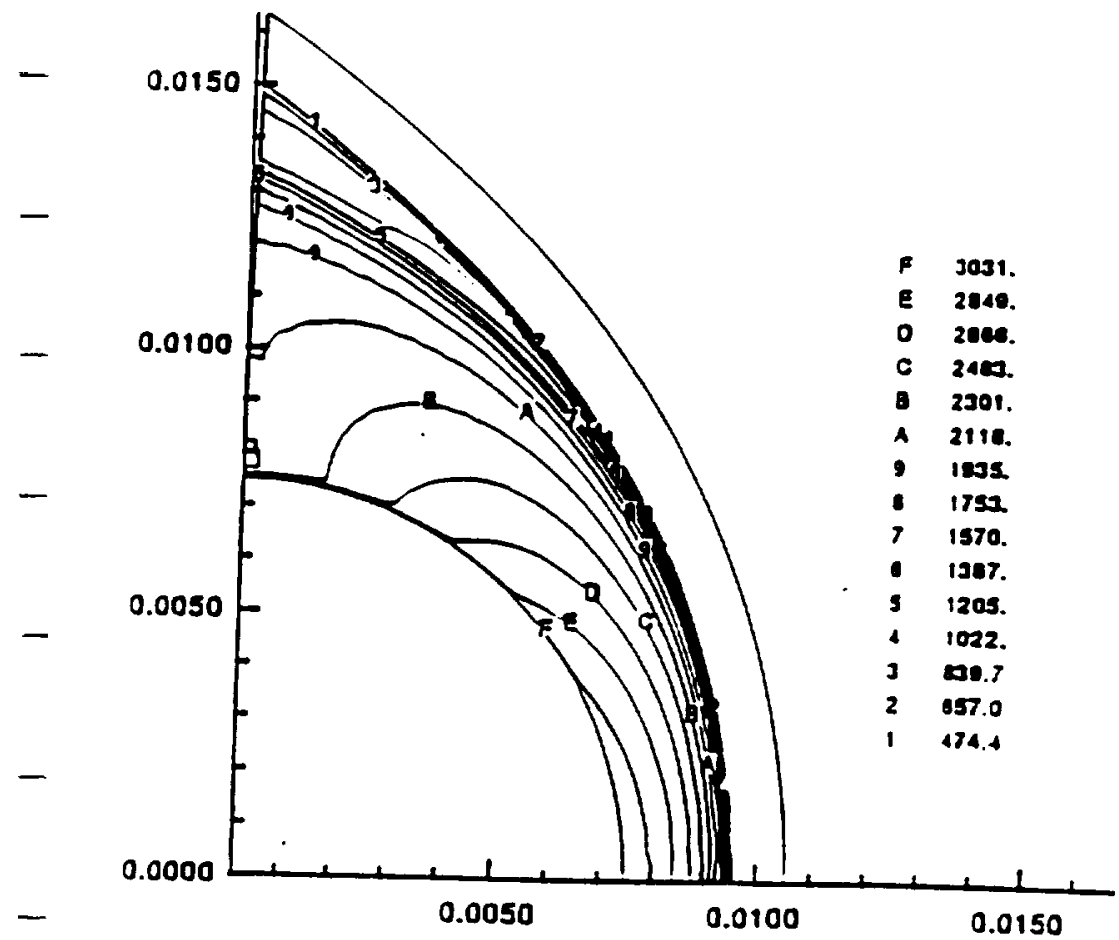

Figure 20 Temperarure contours for Wach 6.46 